\title{
Tatsächliches und Hypothetisches aus der Histopathologie der infantil-amaurotischen Idiotie.
}

\author{
Ton \\ Karl Schaffer. \\ (Aus dem Hirnhistologischen und Interakademischen Hirnforschungsinstitut der \\ Universität Budapest.) \\ Mit 13 Textabbildnngen. \\ (Eingegangen am 4. November 1921.)
}

Aus den einschlägigen Arbeiten wurde die feinste Histopathologie der infantil-amaurotischen Idiotie dermaßen bekannt, daß heute nurmehr gewisse Einzelfragen des Tatsachenmaterials übrig geblieben sind, an deren Lösung aber sich wichtige Fragen der Pathogenese knüpfen. Das mir stetig zufließende Material gestattet diesmal auf Grund eines neueren Falles von Tay-Sachs, den ich meinem verehrten Kollegen Prof. von Bókay verdanke, zwei Punkte einer genaueren Prüfung und Erörterung zu unterwerfen: 1. die Morphologie, Herkunft und chemische Natur der intracellulären Degenerationsprodukte, 2. die Bedeutung der Axonschwellungen. Indem ich mich dabei genau an das zu halten bestreben werde, was die Präparate dem bewaffneten Auge darbieten, möchte ich in diesem Abschnitt nur Tatsächliches aus der Histopathologie der infantil-amaurotischen Idiotie vorführen, worauf in einem nachfolgenden Teil dieses Aufsatzes Erklärungsversuche bzw. deren Kritik folgen sollen, die also nur $\mathrm{H}$ ypothetisches enthalten. Zum Schluß will ich mich ganz kurz über den angefochtenen pithekoiden Bau des Gehirns der infantil-amaurotischen Idiotie äußern, wobei ich gewisse Anlagezeichen erörtern werde, und anhangsweise soll über die Veränderungen des obenerwähnten Falles berichtet werden.

\section{A. Tatsächliches.}

Wir wollen 1. die Nerven-, hernach 2. die Gliazellen ihrem Verhalten nach im Prozeß der Degeneration verfolgen, wobei natürlich die heute schon geläufigen Kenntnisse über die Morphologie der Schwellung unberührt bleiben sollen. Schließlich sollen die Axonschwellungen erörtert werden. 


\section{Nervenzellen.}

Es ist eine bekannte, zuerst durch Schaffer erhobene, später von Alzheimer, Bielschowsky, A. Westphal, Naville, zuletzt von Spielme yer geschilderte Tatsache, daß sich die geschwellten Nervenzellkörper sowie Dendriten mit Degenerationskörnern anfüllen, die auf Markscheidenpräparaten in tiefblauer Farbe zur Darstellung gelangen. Diesen wurde bisher eine mehr summarische Schilderung zuteil; zieht man aber in Betracht, daß sie das Wesentliche des intracellulären Nervenzellprozesses ausmachen, so muß sich ihnen unsere größte Aufmerksamkeit zuwenden. Zum richtigen Studium dieser mit Weigerts Hämatoxylinlackmethode darstellbaren Körner ist eine möglichst exakte Färbung notwendig, die nach meinen Erfahrungen in folgender Weise gelingt. Man beizt in 5 proz. Kaliumbichromatlösung bei Brutschranktemperatur kleine, 0,5-1 cm dicke Stückchen der Großhirn-, Kleinhirnrinde oder des Rückenmarks durch 2-3 Monate, je länger um so sichere Resultate, d. h. um so distinktere Färbung der Degenerationsprodukte in den Nerven- und Gliazellen. Nun folgt eine kurze, etwa 1-2 Wochen dauernde Celloidin-, hernach Paraffineinbettung. Möglichst dünne, ca. $6 \mu$ starke Schnitte kommen auf den mit Eiweißglycerin bestrichenen Objektträger, und nach gehörigem Haften an demselben gelangen die Schnitte abermals in 5 proz. Kal. bichromicum, woselbst sie bei Brutschranktemperatur 3-7 Tage verweilen. Nachher gutes Auswaschen, Färbung nach Weigert - Kultschitzky im Brutofen 24-48 Stunden, und nach mehrstündigem Auswaschen Differenzieren nach $\mathrm{Pál}$, wobei man bedacht sei, daß weder eine Unter- noch Überdifferenzierung stattfinde, denn erstere gibt eine schmutzig-braune diffuse Färbung des Präparates, die die genaue Analyse sehr hindert, letztere aber bleicht abnorm die Hämatoxylinfärbung der intracellulären Degenerationskörner. Zum Schluß kommen die Präparate in eine gesättigte warme Lithiumlösung, wo sie so lange verweilen, bis die hämatoxylingefärbten Stellen eine tiefblaue Färbung annehmen. Nun folgt. Auswässerung, Kontrastfärbung mit Pikrofuchsin, kurzes Wasserbad, Alkohol, Xvilol, Balsam. Mit dieser Methodik gelang mir die Darstellung von Degenerationskörnern an Schnitten, die ohne gehörige Bichromatbeize nicht die geringste Andeutung von diesen enthielten. In der Schilderung dieser Produkte gehe ich von den ersten Spuren derselben aus und verfolge diese sukzessive bis zu ihrer Höchstentwicklung bzw. Rückbildung.

Es wäre vor allem auf den Umstand zu verweisen, daß die Rindennervenzellen bei hochgradiger Schwellung in einem vorgeschritteneren Stadium der Degeneration sich befinden als die Rückenmarksnervenzellen, und weil beim genetischen Studium der Degenerationsprodukte eine richtige Auswahl des Objektes sehr ratsam ist, so beginnt man 
mit Präparaten des Rückenmarks, wo man ein anfänglicheres Stadium der Produktenentwicklung vor sich hat. Besonders erscheinen die Hinterhorn- und Mittelzellen in einer Schwellung, die das Spongioplasma vorzüglich zur Darstellung bringt, indem die Netzlücken klaffend werden, in welchen sich aber keine geformte Degenerationsmasse nachweisen läßt, d. h. weder mit S-Fuchsin am Weigertschen Markscheidenpräparat, noch mit Scharlachrot oder Osmium. Möglich wäre, daß Alzheimers Säurefuchsin-Lichtgrünfärbung eine Körnelung er-

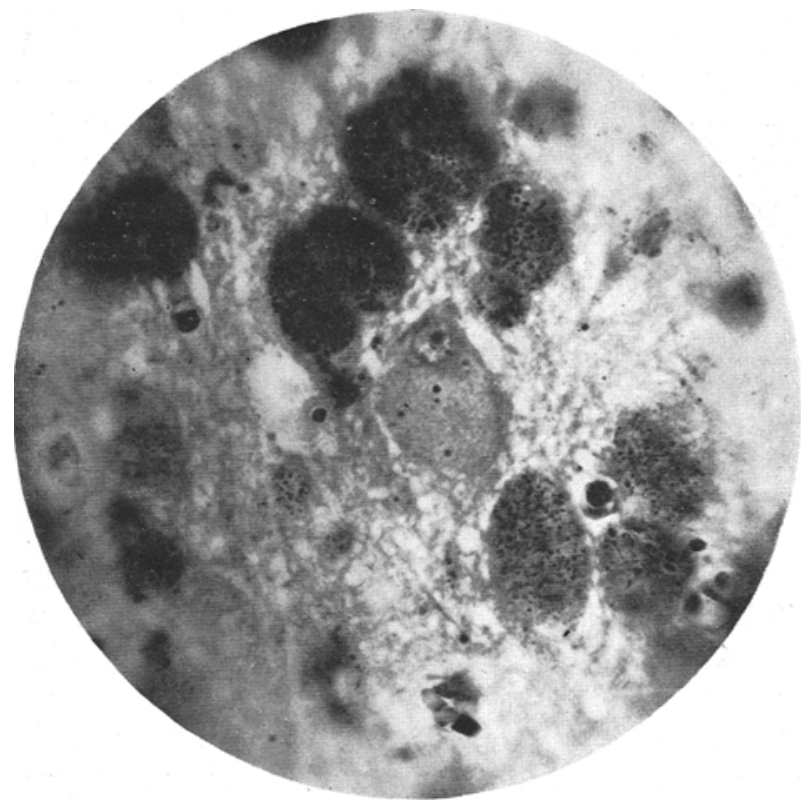

Abb. 1. Immersionsmikrophotographie aus der Großhirnrinde von Tay - S a chs. Zwischen Nervenzellen, die lecithinoid-körnig degeneriert sind, erscheint im Zentrum des Aufnahmefeldes eine in der Quellungsphase befindliche Nervenzelle, deren Kern infolge der Zelleibblähung gegen den Apikalfortsatz gedrängt ist. Der Zelleib zeigt unter dem Mikroskop ein spongioplasmatisches Gerüst, in dessen Lücken allein 6 lecithinoide, kleine Körnchen enthalten sind, welche die erste Spur einer degenerativen Fällung darstellen. Markscheidenfärbung + Pikrofuchsin.

geben dürfte, wie dies H. Spatz für die scheinbar homogene Schwellung der Nervenzellen bei traumatischen Eingriffen, Creutzfeldt für die geblähten Thalamuszellen bei einer degenerativ-familiären Krankheit nachweisen konnten. Doch erscheint diese fuchsinophile Körnelung bei weitem nicht so reichlich, um die Blähung der Nervenzelle allein zu erklären, und somit ist das offenbar durch Flüssigkeitsaufnahme geschwellte Protoplasma der eigentliche, primäre schwellende Faktor; erst aus diesem entwickeln sich im ferneren Verlauf die degenerativen Körner. Tatsächlich erblickt man im Rückenmarksgrau einzelne Nervenzellen, die in den klaffenden Netzlücken rundliche, die Lücken aus- 
füllende Kömer enthalten, wobei zu bemerken wäre, daß diese nicht den ganzen Zelleib, sondern immer nur einzelne Abschnitte desselben anfüllen. Zumeist im selben Zellexemplar erblickt man entweder in zwei bis drei Netzlücken teils aschgrau, teils bläulich-schwarz gefärbte rundliche Körner, die nicht immer lückenausfüllend, sondern bedeutend kleiner sein können; solche Körner, besonders in stärkerer Entwicklung, können einen Pol des Zelleibs besetzen, sonst erscheinen sie spärlichdiffus (s. Abb. 1). Besonders im Rückenmark bekommt man Nervenzellen zu Gesicht, deren Zelleib teils scheinbar leere, klaffende Netzlücken, teils fuchsinophile, teils mit Hämatoxylin aschgrau-bläulich gefärbte Körnchen aufweist, und so sieht man manchmal ein recht buntes Bild. Ein vorgeschritteneres Stadium stellen Nervenzellen dar, deren Zelleib fast ganz mit hämatoxylinaffinen Körnern besetzt ist, und solche findet man in stärkster Ausbildung in der Großhirnrinde.

An dieser Stelle dürfte die genauere Schilderung des mikroskopischen Bildes solcher mit hämatoxylinaffinen Körnern vollgepfropften Nervenzellen aus dem Grunde angezeigt sein, da ich in der Literatur, von Alzheimers flüchtigen Bemerkungen abgesehen, nirgends eine solche fand. Man spricht nur im allgemeinen über mit Hämatoxylin färbbare Körner, ohne deren feinste Morphologie zu berühren; wir werden bald sehen, daß die Formenanalyse dieser Körner nicht belanglos ist. - Überblickt man eine große Zahl von geschwellten und mit hämatoxylinaffinen Körnern besetzten Nervenzellen, so fällt ohne weiteres auf, daß die Form und Tönung der Degenerationskörner keine gleichförmige ist. So wäre vor allem darauf zu verweisen, daß es Nervenzellen gibt, deren Zelleib bzw. deren geblähte Dendriten mehr aschgraue bzw. lichtblau tingierte Körner von ausgesprochen polygonaler Form enthalten, die keineswegs ungezwungen, sondern vielmehr und im gewissen Sinn angeordnet gelegen sind, indem sie um den Kern herum eine mehr oder minder gut erkennbare radiäre Lagerung aufweisen können (s. Abb. 2a). Dann gibt es auch Nervenzellen, die solche polygonale Brocken mosaikartig nebeneinander gereiht enthalten (s. Abb, 2b) und man kann bei aufmerksamer Immersionsbetrachtung oft mit S-Fuchsin rosarote Knotenpunkte des Spongioplasmas zwischen den Körnern erblicken. Aus diesen Bildern geht hervor, daß die wechselnde Form der spongiösen Netzlücken die Form und Anordnung der hämatoxylinaffinen Körner bestimmt.

Eine weitere Entwicklung des degenerativen Schwellungsprozesses bedeutet jene Phase, in welcher die Gerüstzeichnung des Spongioplasmas teils verschwommen, teils ganz aufgelöst erscheint, somit die einzelnen hämatoxylinaffinen Körner förmlich frei werden und nun sich ganz abrunden, wobei sie eine tiefblaue Tönung annehmen. Nun ist der Zellleib bzw. die lokale Dendritblähung mit gleichgroß erscheinenden und 
ganz ungezwungen liegenden Kügelchen, die entschieden Schrotkörnern ähneln, dicht besetzt (s. Abb. 3).

Eine terminale Entwicklungsform kommt dadurch zustande, daß die Degenerationskörner zunehmend kleiner und blasser sich färbend auch spärlicher werden, woraus auf einen Schwund bzw. weitere Transformation derselben zu folgern wäre. In solchen Nervenzellen sah ich mit Scharlachrot allein eine diffus-rötliche Orangetönung ohne die

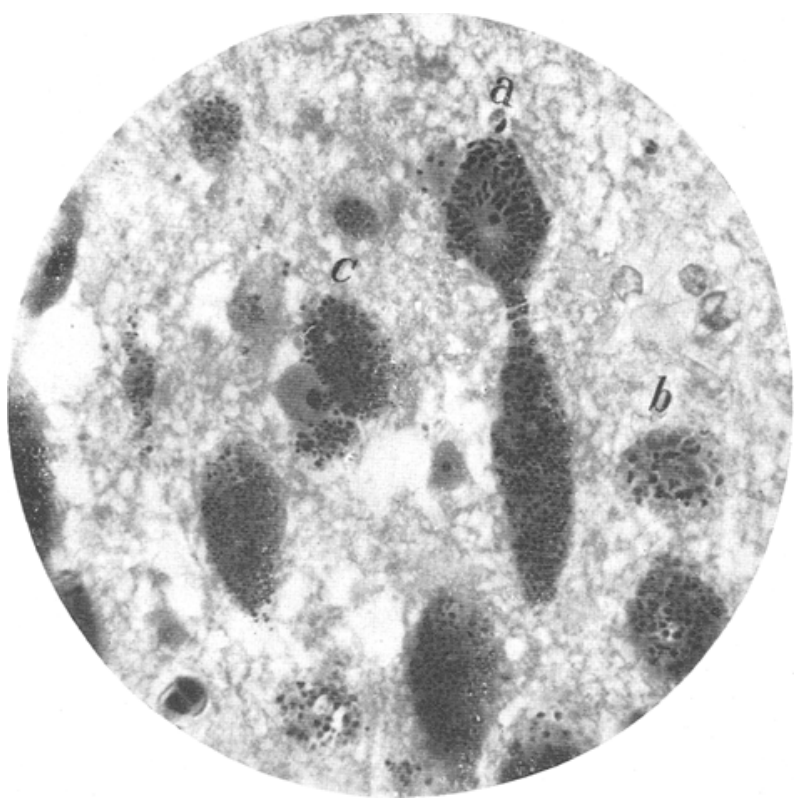

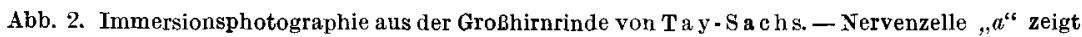
im kernhaltigen Zelleib wohlgeformte lecithinoide Körner von prismatischer oder stricheliger Erscheinung, die eine radiäre Gruppierung um den Kern herum erkennen lassen. Aus dem Zelleib ein beutelartiger Fortsatz basalwärts, dieser entspricht einem geblähten basalen Dendriten, der mit abgerundeten und verkIeinerten lecithinoiden Körnern angefüllt ist. - Nervenzelle,$b^{6 \kappa}$

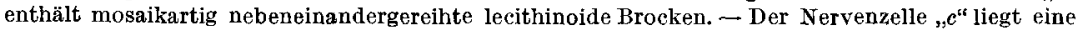
apolare, von haematoxylinaffinen Körnern noch freie Gliazelle an. - Die Figur gibt die Fällungsphase wieder.

bekannten leuchtend-roten Körnchen als die erste Spur einer Lipoidmasse; wir könnten in solchen Fällen nur von einer Prälipoidphase der intracellulären Degeneration sprechen.

Überblicken wir die oben geschilderte Erscheinungsweise der intracellulären Degenerationskörner, so ergibt sich folgendes: Es treten in präformierten, weil spongioplasmatischen, aufgeblähten Lücken protoplasmatische Fällungen auf, die anfänglich durch S-Fuchsin, im weiteren Verlauf durch Weigerts Hämatoxylin hellblau bzw. tiefblau gefärbt werden, daher in ihrer unreifen Form zum Fuchsin, in ihrer reiferen Form zum Hämatoxylin eine Affinität bekunden. Wohlbemerkt sei es, 
daß die einleitende Phase zu diesen Degenerationskörnern das geblähte und scheinbar, d. h. mikroskopisch-leere spongioplasmatische Gerüst darstellt, womit gesagt ist, daß in den Netzlücken ganz zu Beginn das offenbar durch Flüssigkeitsaufnahme geschwellte Proto-

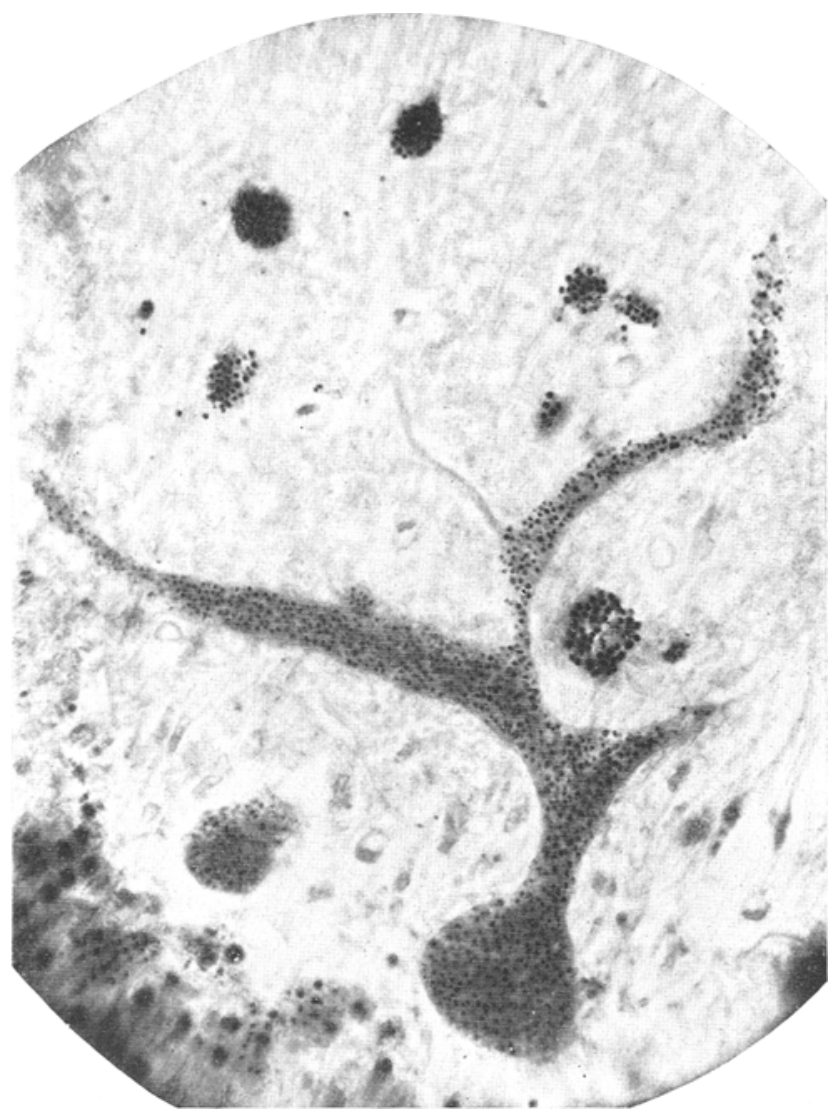

Abb. 3. Immersionsphotographie aus der Kleinhimrinde von Tay-Sachs. - Purkinjesche Nervenzelle, deren geblähte Dendritverästelung reichlich mit kleinen, kugeligen lecithinoiden Körnern vollbesetzt ist mit Ausnahme eines einzigen Astes, der als normaler, nicht geblähter auch keine Degenerationskömer enthält. Unmittelbar oberhalb vom Stammdendrit ist eine kleine geblähte Korbzelle zu sehen, deren Zelleib tiefblau tingierte, eng nebeneinanderliegende, Schrotkörnern ähnelnde Degenerationskörner aufweist. In der Molecularis zerstreut befĩnden sich kleinere Nervenzellen, mit haematoxylinaffinen Körnern beladen, die keineswegs mit gliösen Wanderelementen zu verwechseln sind.

plasma $=$ Hyaloplasma sich befindet. Letzteres allein kann als Gr und masse der Degenerationskörner betrachtet werden, denn die differenzierten Zelleibbestandteile, so die Fibrillen wie auch anfänglich die Nißl-Körperchen, erweisen sich als erhalten. Allein die Frage könnte aufgeworfen werden, ob die basophil-chromatische Substanz, deren pro- 
gressiver Schwund für die amaurotische Idiotie bekannt ist, zur Bildung der Degenerationskörner verwendet wird. Dies auch angenommen, erleidet der hyaloplasmatische Ursprung der Degenerationsprodukte keine Einbuße; ist es doch eine experimentelle Tatsache, daß die NißlKörperchen sich regenerieren können, und dies kann anerkanntermaßen allein aus dem ungeformten Hyaloplasma erfolgen. Auf Grund dieser Betrachtungsweise erscheint die Entwicklung der Degenerationskörner aus der Nißl-Substanz prinzipiell übereinstimmend mit dem Ursprung derselben aus dem Hyaloplasma.

Die Degenerationskörner des Zelleibs sind heute schon wohlbekannte Erscheinungen. Auch hinsichtlich des Chemismus derselben, besser gesagt in bezug der tinktoriellen Reaktionen derselben verfügen wir heute über Kenntnisse, die uns darüber belehren, daß die Körner eine sukzessiv vonstatten gehende Verfettung durchmachen, wobei hochmolekulare Fettsäuren in einfachere übergehen. Schon die Färbung der initialsten Degenerationskörner mit S-Fuchsin, später mit Weigerts Hämatoxylin bzw. mit Ehrlichs Säurehämatoxylin (Schaffer) bekundet die myelinoide Art der Degenerationsprodukte, und da aus F. Reichs mikrochemischen Untersuchungen bekannt ist, daß von den Myelinkomponenten speziell das Lecithin eine distinkte Affinität gegen obengenannte Färbemittel aufweist, so wäre die Annahme von lecithinoiden A b ba u prod u kten im Nervenzelleib sehr naheliegend. Die weitere chemische Veränderung äußert sich im Auftreten von Lipoidmassen, darstellbar durch das Scharlachrot, und eine noch weitere Spaltung bedeutet die Transformation der Lipoidkörner in osmioreduktive. Diesen fortlaufenden Verfettungsproze $ß$ illustriert die familiäre Idiotie durch seine verschiedenen Typen: die fuchsinophile und lecithinoide bzw. prälipoide Phase vertritt die infantil-amaurotische, die lipoide Phase die juvenil-amaurotische (Fall von Schob), die osmioreduktive Phase die ohne Erblindung einhergehende familiäre Idiotie der Erwachsenen (Fälle von F. K. Walter). Es ist unverkennbar, daß zwischen dem Alter des familiär-idiotischen Prozesses und der Verfettungsstufe eine enge Parallele besteht; die akut verlaufende infantile bringt es nur zur Entwicklung von myelinoiden, die juvenile Form bereits zu lipoiden, die Form der Erwachsenen endlich zu osmioreduktiven Degenerationsprodukten. Je protrahierter der Verlauf, um so ausgereifter die intracelluläre Degenerationsmasse im Sinne der Verfettung. - Histopathologisch handelt es sich um die Ausbildung des sog. Abnutzungspigments gemä $\beta$ der Schilderung von Oberndorfer (Zeitschr. f. d. ges. Neurol. u. Psychiatr. 26, 1), das durch einzelne Autoren mit dem Namen Li pof uscin belegt wurde; dieser Stoff färbt sich mit basischen Farbstoffen (Neutralrot, Nilblau), mit Fettfarbstoffen (Sudan III, Scharlachrot), mit den Methoden von Fischler, 
mit Weigerts Markscheidenfärbung, mit Osmium, hingegen verhält es sich refraktär gegen Silbernitrat.

Dieser Chemismus der Degenerationskörner ist jedoch nicht das eigentliche Ziel meiner Darstellung, denn diese bezweckt vielmehr den Ursprung derselben darzulegen. Um letzteren richtig zu erkennen, hat man folgende Tatsachen vor Augen zu behalten. Vor allem sieht man im frühzeitigsten Stadium seitens der degenerierenden Nervenzellkörper ausschließlich das klaffende spongioplasmatische Netz nebst gewahrten Fibrillen und zumeist aufgebrauchten peripheren Nißl-Körperchen; der geschwellte Zellkörper enthält noch keine die Auftreibung bedingende Körnermasse, und so scheint die Annahme berechtigt zu sein, wonach es in diesem ganz anfänglichen Stadium um eine durch Flüssigkeitsaufnahme bedingte Quellung des ungeformten Protoplasmas, d. h. des Hyaloplasmas handelt. Solchen Bildern begegnet man nicht so sehr in der Großhirnrinde als im Rückenmarksgrau, und da ist es dann recht überraschend, die spinalen Nervenzellen fast ganz frei von lecithinoiden Körnern anzutreffen, mit welchem Verhalten die mit solchen Degenerationsprodukten strotzend angefüllten Rindenzellen auffallend kontrastieren. Man hat diese Tatsache so zu deuten, daß die Rindenzellen frühzeitiger die mit $S c h w e l l u n g$ einhergehende Degeneration erleiden als die Rückenmarkszellen, somit setzt der Prozeß bei der infantil-amaurotischen Idiotie früher in der Großhirnrinde ein. Wennschon dieser ein allörtlicher ist, so scheint er doch vom Grau des Endhirns gegen das Rückenmark abzusteigen, ist daher an der Ausgangsstelle entwickelter weil älter. Die Richtigkeit dieser Auffassung wird durch Fälle von Tay-Sachs verschiedener Intensität nachgewiesen, denn die lecithinoiden Körner treten nur im Fall intensivster Degeneration auch in den Rückenmarkszellen auf. Einen solchen hatte ich im Bóka yschen Fall vor mir, dessen Rindengrau zahlreiche formlose Nervenzellen darbietet, in welchen die lecithinoiden Körner selbst eine Lichtung, Verminderung und Abrundung nebst defekter Färbbarkeit zeigen; die Rückenmarkszellen sind im Gegensatz hierzu wennschon gebläht doch nicht formlos, sie befinden sich überwiegend im Stadium des klaffenden Spongioplasmas, in welchem partiell fuchsinophile homogene Massen, dann gefällte fuchsinophile runde Körner bzw. lecithinoide Körner in den spongioplasmatischen Lücken anzutreffen sind. - Die zweite Erscheinung, die das anfängliche Anschwellen des Hyaloplasmas beweist, sind geblähte Zellkörper mit rötlich gefärbtem homogenem Protoplasma; dieses Stadium bedeutet gegen das soeben geschilderte eine Weiterentwicklung und kommt dadurch zustande, daß die spongioplasmatischen Lücken durch ein bereits mit Fuchsin färbbares Hyaloplasma ausgefüllt werden. Erst aus dieser pathologischen Grundmasse entwickeln sich die mikroskopisch verfolgbaren Degenera- 
tionsprodukte im Sinne einer fortlaufenden Verfettung, deren primitivste Phase die fuchsinophilen, höchste Phase die osmioreduktiven Körner darstellen. Wie sehr diese Körner sich aus der hyaloplasmatischen Grundmasse entwickeln, darauf deutet ihre Lagerung in den spongioplasmatischen Lücken, wobei sie sich der Form letzterer genau anpassen. Aus diesen anfänglichen Verhältnissen der intracellulären Degeneration dürfte deutlich hervorgehen, da $\beta$ es sich bei der familiären Idiotie um einen dem Ursprung nach hyaloplasmatischen Degenerationsprozeß handelt, der in seinem späteren Verlauf durch den Zerfall der geformten Zelleibbestandteile, in erster Linie des intracellulären wabig-fibrillären Gerüstes, wohl eine Beimengung erfahren kann, wodurch die Degenerationsmasse quantitativ vergrößert und qualitativ komplizierter wird.

Worauf es mir in obigen Feststellungen ankam, ist der Umstand, daß die a nfänglichs te Schwellung gemäß dem Stande unserer heutigen Färbetechnik nicht durch Ansammlung einer entsprechend großen Menge von Degenerationskörnern, sondern durch Quellung des Hyaloplasmas bedingt wird. Dieser Tatsache begegnet man oft an den geblähten Abzweigungsstellen der Purkinjeschen Dendriten, die eine absolut homogene, mit S-Fuchsin intensiv rosarot gefärbte, abnorm große Masse enthalten. Freilich wird im späteren Degenerationsstadium die Schwellung auf Grund einer Anschoppung von lecithinoiden Körnern vorgetäuscht. Denn letztere stellen nur mehr die gefällte hyaloplasmatische Masse dar, die aus dem formlosen gequollenen Protoplasma auf Grund chemischer Transformation sich zu einer körnigen Masse herausbildet. Zur Verfolgung dieser Verhältnisse ist die infantile Form der familiären Idiotie allein geeignet, wo nämlich ganz anfängliche Bilder der Schwellung zur Beobachtung gelangen; die juvenile Form weil chronisch-protrahiert, bietet nur mehr viel spätere Stadien der Schwellung dar, in welchen natürlich nichts von einem gequollenen Hyaloplasma zu sehen ist, sondern nur hyaloplasmatische Fällungen, d. h. Degenerationskörner teils in lipoider, teils in osmioreduktiver Phase zur Beobachtung gelangen.

\section{Gliazellen.}

Wir haben das Verhalten der apolaren und der dendritischen Glia bei der infantil-amaurotischen Idiotie getrennt zu verfolgen.

a) Die a polaren Gliazellen stellen im nor malen Nervengewebe ein untätiges, besser gesagt unbeschäftigtes Element dar, dessen Tätigkeit erst bei Erkrankungen des Nervenparenchyms einsetzt, wodann es „,aktiviert" wird; aus diesem Grunde dürfte ihr der von E. Pollak vorgeschlagene Name „Bereitschaftszelle" sehr entsprechen. Dabei wäre hervorzuheben, daß diese Zellart infolge ihrer Lage im Lymphraum und vermöge der Fortsatzlosigkeit zum Transport wie geschaffen 
ist; durch Umfließen von Gewebstrümmern schwillt der Zelleib an, bildet A. Jakobs Myelophagen bzw. die Körnchen- oder Gitterzellen, die auf Grund ihres plastisch schmiegbaren Körpers durch die Gewebsspalten bis zur perivasculären gliösen Grenzhaut vordringen und nun durch diese zu schlüpfen vermögen, wie dies zuerst Held zeigte und wie ich mich selbst durch direkte Beobachtung an Präparaten der infantil-amaurotischen Idiotie überzeugen konnte. Die apolare Gliazelle ist eine migrations- bzw. transmigrationsfähige Gliazellart, die echte Wanderglia, die man unter anderen besonders bei Tay-Sachs massenhaft und rein, $d$. h. ohne Beimengung mesodermaler Wanderelemente zu Gesicht bekommt. In diesem Fall sieht man deutlich den von Abbauprodukten besetzten Zellkörper sich den vielgestalteten und durch plasmatische Gliafortsätze gebildeten Gewebslücken anschmiegen, daher in die allerfeinsten Spalten eindringen, eine offenbar sehr langsame Fortbewegung bekunden; infolge dieser Durchzwängung gelangt die gliogene Körnchen- bzw. Gitterzelle zur gliösen Grenzhaut der Gefäße, wo man im günstigen Fall die Passage folgendermaßen beobachten kann. Der Zelleib dieser transmigrierenden Gliazelle besteht aus einer Einschnürung und zwei polaren Anschwellungen; erstere befindet sich genau in der Grenzhaut, von welcher diesseits also noch im Gliagewebe bzw. Nervenparenchym die eine, jenseits, d. h. im adventitiellen Lymphraum, die andere polare Anschwellung der gliösen Wanderzelle liegt (s. Abb. 4). Nach beendetem Durchschlüpfen befindet sich die gliogene und nun ganz abgerundete Wanderzelle ganz im vasculären Lymphraum, der mit solchen Elementen manchmal recht dicht besetzt, förmlich austapeziert sein kann. - Doch nicht allein durch die Membrana limitans gliae perivascularis, sondern auch durch die M. 1. gl. superficialis dringen die apolaren Elemente, wie man dies sehr schön in der Kleinhirnrinde bei Ta y - Sachs sieht. Hier gruppieren sie sich in der Molecularis reihenförmig, als wären sie im Gänsemarsch begriffen, gegen die Oberfläche zu, und jene Elemente, die ganz zonal liegen, zeigen verschiedentliche Auswüchse ihres Protoplasmas und repräsentieren in dieser Form eine echte amöboide Glia; dann sieht man Exemplare, die halb noch innerhalb, halb außerhalb der Kleinhirnrinde liegen, schließlich haben sie die Oberflächengrenze überschritten und befinden sich subpial bzw. intraadventitiell.

Die Wanderung der apolaren Elemente aus dem ektodermalen Gewebe in das mesodermale hinein verfolgte ich so in der grauen wie weißen Nervensubstanz. Was nun aber im übrigen ihr Verhalten an diesen beiden Stellen anbelangt, so erheischt dies eine eigene Darstellung. In der weißen Marksubstanz erscheinen besonders an Punkten des stärksten Zerfalls von Markscheiden wie von Axonblähungen apolare Gliazellen, deren vergrößerter Zelleib Markscheidenbrocken von ver- 
schiedener Größe enthält; auf Grund von Übergängen läßt sich mit großer Wahrscheinlichkeit annehmen, daß infolge zunehmender Verkleinerung dieser Myelinüberreste deren Abbau in lipoide, mit Scharlachrot intensiv gefärbte Körnchen erfolgt, wobei der gliöse Zelleib noch mehr anschwillt und das Äußere einer Gitterzelle annimmt; mit solchen Elementen ist der vasculäre Lymphraum vollbesetzt. Die apolaren Gliazellen der grauen Rindensubstanz liegen teils in Gewebs -

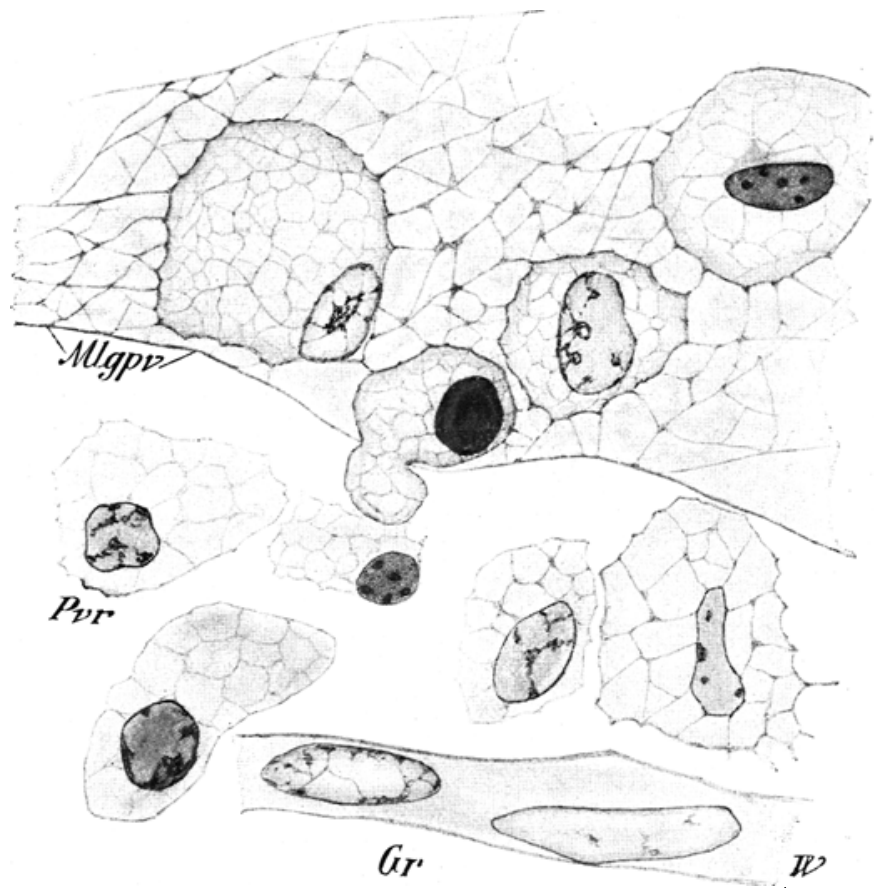

Abb. 4. Zeichnung aus der Großhirnrinde von Tay - Sachs, darstellend die Wanderung der apolaren Elemente. - Mlgpv Membrana limitans gliae perivascularis. Pvr Perivasculärer Raum, in welchem sich 5, die gliöse Grenzhaut bereits passierte grobgittrige apolare Elemente befinden; ein Element, ausgezeichmet durch seinen tiefgefärbten Kern, passiert eben die Grenzhaut. - W Kapillarwand mit Endothelkernen. Gr Gefäßraum, dessen Abgrenzung durch die mit $W$ parallel verlaufende andere Wand in der Zeichnung nicht zur Darstellung kam. Van-Gieson-Färbung.

spalten als rundliche Elemente, deren Zelleib auffallend tief und matt rosarot gefärbt erscheint, teils schmiegen sie sich dem geschwellten Zelleib oder dem apikalen oder basalen Dendrit der Nervenzelle an; im letzteren Fall entfalten sie eine halbkreisförmige einbuchtende Wirkung auf den Zelleib bzw. Dendrit, wodurch manchmal tiefe Einschnürungen entstehen können (s. Abb. 5). In diesem Verhalten ist der Anfang zu einer neuronophagischen Tätigkeit gegeben; der relativ kurze Ablauf des Krankheitsprozesses bei der infantil-amaurotischen Idiotie gestattet nicht die Ausbildung einer terminalen Neuronophagie, 
d. h. das Zustandekommen von sog. Restknötchen, welche die an Stelle der aufgelösten Nervenzelle entstandene gliöse Zellanhäufung bedeuten, obschon äußerst spärlich auch solche Bildungen vorkommen. Interessant ist der Zelleib solcher gliösen Begleitzellen; man bemerkt in diesem hämatoxylinaffine Körner, die morphologisch und tinktoriell ganz jenen des Nervenzelleibs entsprechen, myelinbrockenartige Partikelchen kamen mir niemals zu Gesicht. Aus diesem Verhalten folgt, daß die gliösen apolaren Elemente hinsichtlich ihres Zelleibinhalts in der weißen und grauen Substanz different sind und während wir in der Mark-

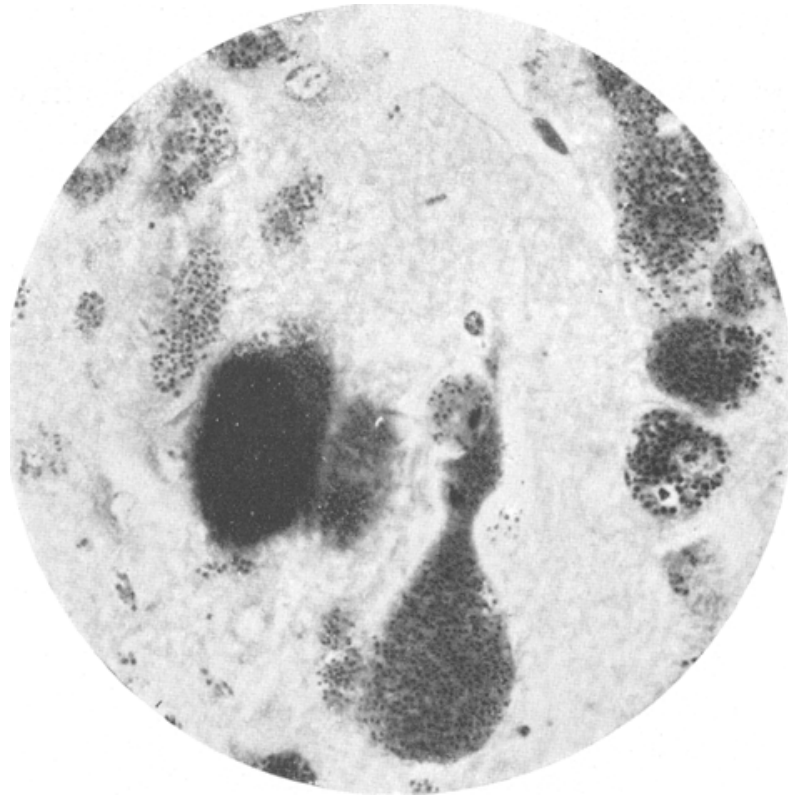

Abb. כ. Immersionsphotographie aus der Großhirnrinde von T a y-S a c h s. Die basal-geblähte Nervenzelle (hier angefüllt mit kleinen lecithinoiden Körnchen) zeigt ihrem Zelleib eng angeschmiegt ein geblähtes apolares Element, dessen Körper, zerstreut lecithinoide Körnchen enthaltend, den Zelleib der Nervenzelle tief einbuchtet, somit den Beginn einer Neuronophagie darste1lt. - Markscheidenfärbung + Pikrofuchsin.

substanz eine direkt-mechanische Aufnahme von Myelinfragmenten seitens der apolaren Gliazellen anzunehmen haben, dürften die hämatoxylinaffinen Körner derselben in der Rindensubstanz mehr auf osmotischem Wege zustandekommen gedacht sein. Mit der Zuhilfenahme von osmotischen Wirkungen begebe ich mich auf das Gebiet der Hypothese, welches Vorgehen in diesem Abschnitt über Tatsächliches wohl nicht hineinpaßt, doch zwingt mich hierzu die Darstellung. Es wäre nämlich anzunehmen, daß die den geschwellten Nervenzellen eng angeschmiegten gliösen Begleitzellen infolge von Membranfunktionen zur Aufnahme des veränderten Hyaloplasmas gelangen und somit einen 
Stoff erhalten, der in ihrem Körper ebenso zuerst eine lecithinoide Metamorphose durchmacht wie im Nervenzelleib, ja hier vermöge lebhafterer fermentativer Wirkung rascher verfetten als in der Nervenzelle, worauf die prälipoide bzw. feinkörnig-lipoide Färbung mit Scharlachrot hinweist, während gleichzeitig der Nervenzellkörper noch keine Andeutung ähnlicher Farbreaktion gibt. Hingegen erscheinen die apolaren Gliazellen der weißen Substanz intensiv verfettet, da sie mit leuchtendroten gröberen Lipoidkörnchen dicht besetzt erscheinen, ein Verhalten, welches angesichts der Aufnahme von bereits fettartigen Myelinbrocken leicht begreiflich ist.

Um es kurz zu wiederholen: der Inhalt der apolaren Gliazellen ist ein chemisch differenter, je nachdem es sich um solche in der weißen oder grauen Substanz handelt. Die apolaren Elemente der weißen Substanz nehmen durch Umfließen also auf grob-mechanischem Wege Markbrocken i. e. vorlipoide Substanzen in ihren Zelleib auf, während jene der grauen Substanz infolge Osmose also auf mehr biologischmechanischem Wege einen pathologischen Zelleibsaft erhalten, welchen sie mit Hilfe ihrer Fermente zuerst in lecithinartige Degenerationsprodukte spalten, auf welche Phase später die prälipoide bzw. feinkörnig-lipoide folgt; eine derbkörnig-lipoide Phase der corticalen apolaren Elemente sah ich allein in der zonalen Schicht, die bekanntlich zu intensiverer Abnutzung stark veranlagt ist. Es wäre somit zu betonen, daß die apolaren Gliazellen sich immer in einem vorgeschritteneren Stadium der Verfettung befinden als die mit ihnen in engster Berührung stehenden Nervenzellen und das tinktorielle Verhältnis ist ein derartiges, daß, wenn die Nervenzelle gebläht und mit lecithinoiden Körnern gefüllt ist, so erscheint die Begleitzelle diffus hellorangegelb, ist aber die Nervenzelle von letzterer Farbe, so bemerkt man im orangegelben oder rötlichen Zelleib der Begleitzelle feine leuchtend rote Körnchen. Ist endlich sehr vereinzelt die Nervenzelle in letzterer Verfettungsphase, d. h. ihr Zellkörper mit spärlichen und feinsten Scharlachrotkörnern besetzt, so weist die anliegende gliöse Begleitzelle bereits derbe Lipoidkörner auf. Letztere Stufe ist in der Abbauarbeit Alzhei mers in Abb. 5 Tafel XXXIV wiedergegeben, die einen Schnitt durch die Hirnrinde eines infantil-amaurotischen Falles darstellend, in den Ganglienzellen wenig staubförmiges, fein verteiltes Lipoid, in den apolaren Gliazellen haufenförmig derbe Lipoidkugeln zeigt. Die geschwellten Nervenzellen und die gliösen Begleitzellen stehen daher in einem engen Stoffwechselverhältnis zueinander.

b) Die dendritischen Gliazellen bekunden ein Verhalten bei der infantilen Idiotie, die durch keine Methode besser als Ca jals Sublimatgoldimprägnation beleuchtet wird. Es wäre nämlich darauf zu verweisen, daß dieses Verfahren einesteils auf Grund von Form- und 
Kohäsionsveränderungen seitens des gliösen Protoplasmas uns über den pathologischen Zustand des Zelleibs und der Fortsätze unterrichtet, anderenteils besonders Hervorragendes in der Topographie der kranken Glia leistet, denn Präparate nach Cajal lassen bereits bei schwachen Vergrößerungen, also im Übersichtsbild den normalen bzw. pathologischen Zustand der Glia erkennen, ein Umstand, der uns zum Überblick und zur topischen Umgrenzung der gliösen Veränderungen verhilft. Denn Cajals Methode enthüllt uns pathologische Veränderungen, die bei Anwendung anderer Methoden entweder gar nichts oder viel weniger deutlich sichtbar werden. Und schließlich leistet diese Methode in bezug des Verhaltens der Glia um die Gefäße herum Vorzügliches. Halten wir diese Qualitäten der Cajalschen Gliamethode vor Augen, so ist es unschwer, einzusehen, daß diese speziell in der Darstellung eines ausgebreiteten bzw. allörtlichen Degenerationsprozesses der Glia unentbehrlich ist, ja man kann ruhig behaupten, daß dieser allein mit genanntem Verfahren übersichtlich und überzeugend zu demonstrieren ist. Dabei darf man nicht vergessen, daß diese Methode eine mehr morphologische ist, welcher gegenüber die färberisch-mikroskopischen Methoden der Glia von Alzhei mer stehen, die in tinktoriellen Differenzen die chemisch verschieden abgestuften Abbauprodukte -die fibrinoiden, die fuchsinophilen usw. Granula - wiedergeben.

Die dendritischen Gliazellen der Großhirnrinde bei Tay-Sachs bekunden ein Verhalten, das in der oft überraschende Dimensionen darbietenden Hypertrophie des Zelleibs wie der Fortsätze, ferner in dem progressiven Zerfall derselben besteht. Auf Grund der Hypertrophie kommt es zu den bekannten Monsterzellen der tieferen Rindenlagen, die durch ihren opaken Zelleib, mit dem großen bläschenförmigen und zumeist randständigen Kern so am van Gieson schen wie am Bielschowskys Fibrillenpräparat sich kenntlich machen; die Gliadendriten erscheinen als plumpe, elephantiastische Fortsätze, die an der gliösen Gefäßhaut mit knolligen Verdickungen haften. Diese mächtige Anschwellung wird von einer Zerklüftung des Zelleibs gefolgt; es zeigen sich oft ringförmige Spaltbildungen um den Kern herum, dann mehr-minder regellose Diastasen des Zellkörpers und all diese Kohäsionsfehler bilden die Einleitung zum progressiven Zerfall, der zuerst in der Bildung einzelner Blöcke, dann kleinerer Partikel, zuletzt feinerer Körnchen besteht (Gliadendritus). Während dieses morphologischen Zerfalls kommt es auch zur Bildung von chemischen Degenerationsprodukten, die als rundliche, mit Scharlachrot intensiv sich färbende Körner erscheinen. Solche Lipoiddegeneration bemerkt man besonders ausgeprägt in den Astrocyten der obersten Rindenschichten, welche nicht allein in ihrem Leibe, sondern selbst in den Fortsätzen auch zweiter Ordnung einen Lipoidbesatz aufweisen. Bei der infantil-amaurotischen 
Idiotie findet sich, wie dies zuerst A. Westphal nachwies, eine allörtliche Gliaerkrankung, für welche ich (1919) betonte, daß diese ein Seitenstück zur allörtlichen Nervenzellerkrankung darstellt, besitzt daher eine mit letzterer gleichwertige Bedeutung. Diese progressive Nekrose der dendritischen Glia ist eine ,Eigenerkrankung“, womit ausgedrückt sei, daß die Neuroglia in diesem Fall keine Ersatzleistung vollzieht, sondern auf demselben krankhaften Einfluß ebenso reagiert, wie das gleichzeitig erkrankte Nervengewebe.

Die von mir 1917 angenommene Eigen kran kheit der Glia stützt. sich auf gewisse Kriterien, von welchen ich folgende anführe. Als ein Kriterium betrachtete ich die Unabhängigkeit der gliösen Veränderungen von den nervösen, wie ich dies z. B. bei der progressiven Paralyse fand, indem hier weitverbreitet eine kolossale, gleichmäßige Hypertrophie der gliösen Astrocyten besteht, eine Erscheinung, die keineswegs als Ersatz für das nicht adäquat degenerierte Nervenparenchym angesehen werden kann. Ein weiteres Kriterium der eigengliösen Erkrankungen ist die koordinierte Affektion der gliösen und nervösen Elementen, wie ich dies in schönster Form bei der infantil-amaurotischen Idiotie fand, wo alles Gliöse wie Nervöse gleich intensiv und gleichzeitig degeneriert ist, somit besteht eine vollkommene Parallele, die darauf verweist, daß die beiden ektodermalen Abkömmlinge des zentralen Nervensystems gleichzeitig und gleichintensiv reagierten. Ein drittes Kriterium der gliösen Eigenerkrankung lieferte in allerletzter Zeit E. Polla $k^{1}$ ), der bei akuter Meningitis eine der Nerven parenchymerkrankung vorangehende, daher selbständige Gliaerkrankung der Großhinrinde fand und damit bewies, daß die Glia krankhaften Reizen auch selbständig, förmlich isoliert, unterliegen kann. Dieser Autor unterscheidet als erste Phase eine sog. Reizhyperplasie der dendritischen Glia, die im wesentlichen meiner Hypertrophie und Hyperplasie der Glia entspricht und die er als einen hyperplastischen Regulationsvorgang der Glia im Dienste einer Abwehr des Nervensystems gegen den Angriff auffaßte. Zu dieser Zeit ist das Nervenparenchym noch unverändert, dieses erkrankt in einer später einsetzenden Phase der akuten Meningitis, zu welcher Zeit die Ausbildung von Abräumzellen - Polla ks destruktiver Typus der Gliazelle - erfolgt. Pollak leitet die Abräumzellen gleichfalls von den kleinen Gliazellen, von seinen „Bereitschaftszellen“ ab.

Unmittelbar vor Pollaks Arbeit erschien Spielmeyers Studie über die zentralen Veränderungen beim Fleckfieber, in welcher dieser Autor über sehr interessante Gliareaktionen, hauptsächlich in der Form seines Gliastrauch werks, ferner der Gliarosetten und Gliasterne berichtete.

1) Pollak, E., Studien zur Pathologie der Neuroglia. Obersteiners Arbeiten 22. 1919. 
Ueber diese ist Spielmeyer der Ansicht, ,daß die außerordentliche Gliawucherung in den Fleckfieberherden weit über das Maß einer reaktiven Wucherung nach einem etwaigen primären Zerfall nervöser Elemente hinausgeht" und schließt seine Arbeit mit folgenden Worten: „Wir haben es bei diesen Gliawucherungen wohl auch mit dem Ausdruck einer funktionellen Reaktion auf den einwirkenden Reiz zu tun, wie es Borst für die spezifisch-parasitäre Reize hervorhebt. Das Gliagewebe ist eben nicht eine starre Stützsubstanz, die nur bei Störungen des Gleichgewichts und der Gewebsspannung eine Ausgleichwucherung zu leisten vermag, oder die nur die Aufgabe hat, das zerfallene Material zu entfernen, sondern die auch selbständig Reizen zugänglich ist. Sie kann unter manchen Bedingungen zur Proliferation angeregt werden." Mit dieser Äußerung verläßt Spielme yer ${ }^{1}$ ) auch seinerseits die starre Weigertsche Auffassung und erblickt in gewissen Gliaveränderungen adäquate Reiz-(Noxen-)Reaktionen selbständigen Charakters, wie ich dies für die von mir als Eigenerkrankungen der Glia benannten Veränderungen schon früher (1917) erkannte. Spielmeyer bezeichnete dieselben als selbständige Reizreaktionen der Glia, womit er dasselbe sagt wie ich und betrachtete letztere für prinzipiell bedeutungsvoll, genau so wie ich.

Überblicken wir die Rolle der Neuroglia bei der infantil-amaurotischen Idiotie, so ergibt sich ein zweifaches Verhalten: einesteils macht sich die Aktivität der normal-inaktiven apolaren Gliazellen im Sinne des Abbaus und Abräumens bemerkbar, anderenteils erleiden die dendritischen Gliazellen eine allörtliche, zum völligen Zerfall führende Degeneration. Wohl ist damit die Tätigkeit der Neuroglia nicht erschöpft, denn A. Westphal wies bekanntlich auch eine, besonders im Kleinhirn zur Geltung gelangende Ersatztätigkeit in Form von Verfaserung nach. In letzterer Beziehung wäre der Umstand hervorzuheben, daß nicht ein jeder Fall von Ta $\mathrm{y}$ - Sachs diese Ersatztätigkeit der Glia aufweist, weil eben die Intensität des Degenerationsprozesses nicht immer gleich groß ist. Denn wie es hinsichtlich der Markhemmung bzw. Markdegeneration sehr verschieden intensive Fälle gibt, dermaßen, daß neben ziemlich reichlichem Markgehalt auch Gehirne mit höchstgradigem Markausfall und Degeneration zur Beobachtung gelangen, ebenso gibt es in bezug des Gliabildes verschiedene Varianten. Unter allen Umständen möchte ich aber die Tatsache hervorheben, daß es mir an meinen zahlreichen Präparaten nirgends gelang, die Ausbildung von apolaren Elementen aus verzweigten protoplasmatischen Gliazellen durch Abbruch bzw. Abstoßen der Fortsätze infolge Abrundung des Zellkörpers entstehen zu sehen, wie dies im allgemeinen bekanntlich P. Schröder annimmt.

1) Spielmeyer, Die zentralen Veränder. b. Fleckfieber u. ihre Bedeutung f. d. Histopath. d. Hirnrinde. Zeitschr. f. d. ges. Neurol. u. Psychiatr. 5\%, 48. 1919. 


\section{Axonschwellungen.}

In meinen ersteren Arbeiten hob ich für die Histopathologie der infantilen amaurotischen Idiotie ein mir als sehr bezeichnend erscheinendes Moment hervor: die Unversehrtheit des Axons trotz hochgradiger Schwellung der Ursprungszellen. In meiner zusammenfassenden Arbeit aus dem Jahre 1909 betonte ich diesen Punkt scharf und stellte dem Nervenzentrum i. e. Ganglienzelle als der Aufnahmsstätte von Reizen den Axon als einfachen Reizleiter entgegen, dessen Integrität auf eine Wahl des heredodegenerativen Prozesses in dem Sinne hindeute, daß das Neuron selbst in seinen einzelnen anatomischen Bestandteilen unabhängig bzw. elektiv ergriffen werden kann. Diese nackte Tatsache erheischte eine Erklärung, denn es befremdete bzw. überraschte mich im höchsten Grad, daß der Axon als Neuronbestandteil angesichts der mächtigen Neuronerkrankung, welche in der höchstgradigen Schwellung gegeben ist, an diesem nicht Anteil haben soll. Und als ich mir nun gewisse normal-anatomische Eigenheiten des Axons vergegenwärtigte, namentlich daß der Axon ein besonders gebauter Neuronabschnitt ist, der bekanntlich am Nis s l-Präparat durch den Mangel an Nis s 1-Körperchen vom Zelleib lebhaft absticht, aber auch am Silberpräparat nach Cajal seine morphologisch-abweichenden Eigenschaften den Dendriten gegenüber besitzt, da gelangte ich zur Formulierung einer Auffassung, die besagen wollte, daß der Axon ein sui generis-Bestandteil des Neurons wäre, der nicht allein morphologisch, sondern auch funktionell vom Zelleib bzw. von den mit letzteren identischen Dendriten differiert. Diese dem Axon vindizierte Sonderstellung zog ich zur Erklärung der Intaktheit des Axons bei infantil-amaurotischer Idiotie heran und es sei hervorgehoben, daß Bielschowsky an der Tatsache selbst, d. h. an den morphologisch unversehrten Axonen in seiner jüngsten großen Arbeit ebenfalls festhält.

Da kam es vor einigen Jahren (1913), daß ich mit den Kleinhirnveränderungen bei Tay - Sachs beschäftigt, besonders an den Axonen der Purkinjeschen Nervenzellen Anschwellungen sah, die mit Vorliebe an den Stellen von Kollateralabzweigungen saßen und die ich in zwei Formen antraf, als dunkle, gleichmäßig tingierte und als helle, strukturierte Nodositäten. Während die erstere Art infolge massiver Silberimprägnation nach $\mathrm{Bielschowsk} \mathrm{y} \mathrm{nur} \mathrm{eine} \mathrm{knollige} \mathrm{Anschwellung}$ des Axons sehen ließ, offenbarte letztere ein Auseinanderweichen der normalen Axonfibrillen und deren anastomotisches Geflecht, so daß ich hier die sog. strukturenthüllende Wirkung der lokalen Anschwellung als einen Vorgang erachtete, der den gleichmäßig schwarz imprägnierten Axon in seine Bestandteile zerlegte. Diese Axonschwellungen der Purkinjeschen Nervenzellen wollte ich anfänglich für eine lokale Erscheinung betrachten und fand daher keine Veranlassung, das Prinzip 
der Axonintaktheit bei infantil-amaurotischer Idiotie dadurch durchbrochen zu sehen. Doch bald darauf fand ich in der grauen Substanz des Rückenmarks eines weiteren Falles Axonschwellungen, wohl an einer mehr umschriebenen Stelle und so wollte ich noch immer nicht wirklich Zwingendes für das Verlassen von meinem ursprünglichen Standpunkt erblicken, bis ich dann durch das Rückenmark des letzten Falles von Tay-Sachs eines Besseren belehrt wurde. Es fanden sich im Fasernetz des Vorderhorns an Axonen lokale spindelförmige An-

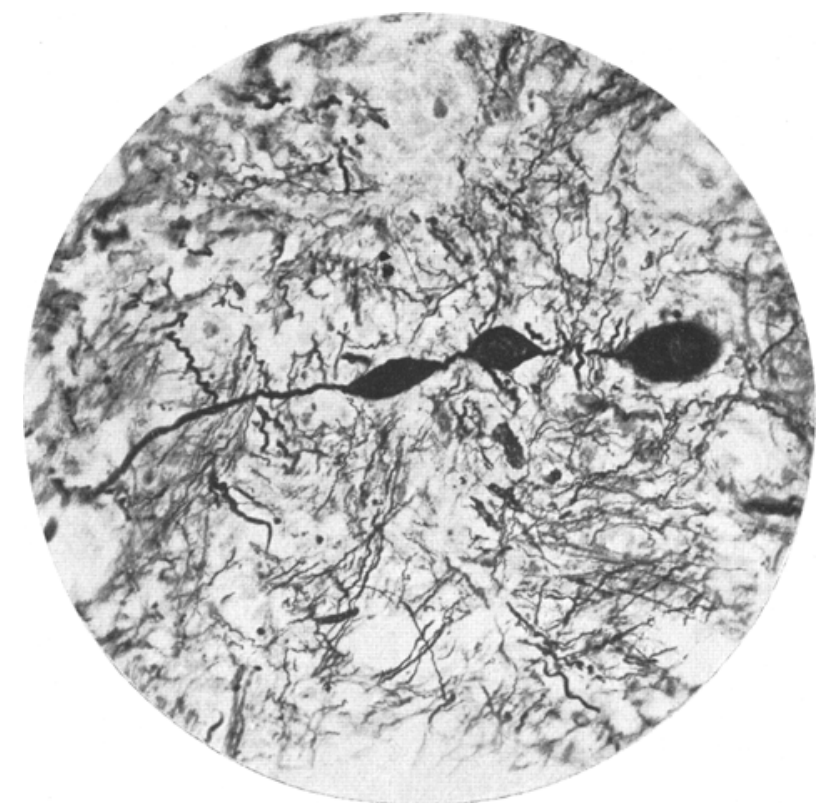

Abb. 6. Immersionsphotographie aus dem Vorderhorngrau von Tay-sachs. - Perlschnurartige Schwellung eines Axons. Bi elschowskys Fibrillenimprägnation.

schwellungen vielfach vor, die manchmal solitär, oft aber auch multipel erschienen, indem sich zwei oder drei ziemlich gleichmäßig große kugelige Blähungen unmittelbar hintereinander reihten ( $\mathrm{s}$. Abb.6). Bemerkt sei, daß streng darauf geachtet wurde, die Nervenfasern nicht mit Dendriten zu verwechseln. Nach diesem Befund handelte es sich um sog. Verlaufsanschwellungen des Axons, die Cajal als varicosidades de trayecto zum Unterschied von den Endanschwellungen - varicosidades terminales - bezeichnet und die der spanische Autor als Endknöpfchenanschwellungen gelten läßt. Meine Präparate gaben aber auch in letzterer Beziehung Beispiele; so sah ich einen schwarzgefärbten Faden an eine Vorderhornzelle heranziehen und hier mächtig schaufelförmig sich verbreitern (s. Abb.7). Doch erfaßte ich sofort 
die wirkliche Bedeutung solcher Gebilde, als ich an einem solchen Exemplar bei aufmerksamer Immersionsbetrachtung einen ganz kurzen dornähnlichen Fortsatz in der linearen Verlängerung des Stieles der Axonanschwellung erblickte und somit ist es mir klar geworden, daß grobkalibrige Endanschwellungen eigentlich verkappte Verlaufsanschwellungen sind, die zu Endanschwellungen durch das zufällige Abhacken des zweiten Poles artefiziell wurden. Ich verhalte mich auf Grund dieser Erfahrung gegen sog. hypertrophische Endknöpfe mehr als reserviert.

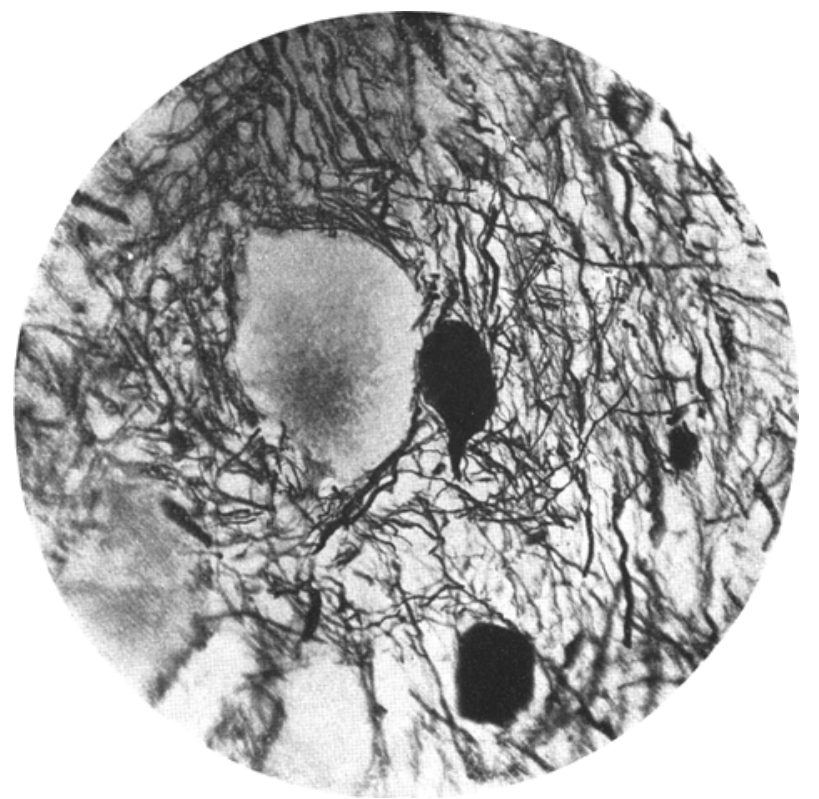

Abb. 7. Immersionsphotographie aus dem Vorderhomgrau von Tay-S a chs. Scheinbare „Endanschwellung“ hart an der Oberfläche einer höchstgradig degenerierten Nervenzelle. B i e Is c h ow s y s Fibrillenimprägnation.

Die Anschwellung ist im Rückenmark eine gleichmäßig tief tingierte und besonderer Struktur wurde ich nicht gewahr. In Zusammenhang mit letzterem Moment möchte ich auf jene Bilder von Axonanschwellungen hinweisen, die ich bei chronischer heredodegenerativer Entmarkung in der weißen Substanz der Großhirnrinde antraf und wo ich Bilder sah, die mit den bei infantil-amaurotischer Idiotie im Rückenmark gefundenen Axonschwellungen übereinstimmten. - Auf die Frage, ob solche Axonschwellung nicht ebensolche Degenerationsprodukte beherberge wie der Nervenzellkörper bzw. Dendriten, wäre zu bemerken, daB der Axon an solcher Stelle mit fuchsinophilen Körnern besetzt erschien und sich dadurch als in jüngster Degenerationsphase befindlich dokumentierte, wie ich dies in dieser Form am zelligen Bestandteil 
des Neurons seltener sehen konnte, denn hier überwiegen die lecithinoiden Körner.

Hinsichtlich des Vorkommens der Vorlaufsanschwellungen im Rückenmark bei infantil-amaurotischer Idiotie ist zu bemerken, daß diese mit Vorliebe in der grauen Substanz des Rückenmarks an markhaltigen Nervehfasern anzutreffen sind; längsschnitte ließen in der weißen Substanz nur viel bescheidenere und spärlichere Anschwellungen sehen, die am Querschnitt nicht zum Vorschein kommen können. Im Windungsmark der Großhirnrinde kommen Axonschwellungen zahlreich vor. Hier wie im Rückenmark erscheinen die Achsenzylinder mit hochgradig geblähten bzw. "Netzfiguren" aufweisendem Mark versehen, aus welchem Umstand die zweifellose Degeneration der Markscheide hervorgeht. Bei diesem Punkt wäre zu betonen, daß nicht ein jeder Fall von Tay-Sachs eine derartig intensive Erkrankung aufweist, denn es gibt Fälle, die nebst distinkter qllörtlicher Nervenzellschwellung ohne erkennbare Axon- und Myelinanschwellung einhergehen können; das sind die Fälle, welche infolge von hürzerem Verlauf eine weniger intensive Degeneration bekundeu.

Suchen wir sehließlich die Bedeutung der Axonschwellungen zu erfassen, so ist es naheliegend, dieselben als Schwellungsphänomene dem universellen Schwellungsproze 1 , der das zentrale Nervensystem bei Ta y-Sachs beherrscht, zuzuweisen. Mit dieser Erkenntnis ist also das Prinzip der Axonintegrität durchbrochen und wir gelangen somit zu einem umfassenderen und einheitlicheren Gesichtspunkt für den Schwellungsprozel3. Die Axonsch wellung macht also eine in tegriere nde Teilerscheinung der Histopathologie der infantil-amaurotischen Icliotie ans und erweitert harmonisch das in der allge meinen neuronalon Schwellung sich kundgebende Bild. Der Axon spielt nicht mehr die Rolle eines sui generis-Bestandteils des Neurons im histopathologischen Geschehen und wenn auch seine Teilnahme im schwellenden Prozeß eine entschieden bescheidenere ist, als jene des Nervenzelleibs und der Dendriten, so hat daran die bekannte Resistenz des leitenden Neuronelements die Schuld. Es wäre nur an das sattsam bekannte Verhalten des Axons zu erinnern, daß bei allen zersetzenden Prozessen der Nervenelemente sich zwei Neuronbestandteile entgegengesetzt verhalten: das Nervenmark und der Achsenzylinder und daß aus höchstgradig erkrankten Nervenzellen morphologisch noch intakt erscheincnde Axone abgehen.

Fine wesentlich abweichende Auffassung hegt Bielschowsk $\mathrm{y}^{1}$ ), der in seiner letzten Arbeit sich dagegen verwahrt, die ,Axonkugeln“"

1) Bielschowsk y, Max, Zur Histopathologie und Pathogenese der amaurotischen Idiotie mit besond. Berücksichtigung der cerebellaren Veränderungen. Journ. f. Psychol. u. Neurol. 26. 1920. 
als Analoga der sack- bzw. ballonförmigen Auftreibungen der Dendriten zu betrachten, indem er sagt: ,Wir haben es hier keinesfalls mit einem dem Schafferschen Zellprozeß gleichwertigen und für das histopathologische Gesamtbild charakteristische Erscheinung zu tun" (S. 136 1. c.) Dagegen spräche, abgesehen von den morphologischen Differenzen, die Tatsache, daß man solche Schwellungen auch bei anderen Krankheiten antrifft, so bei multipler Sklerose, juveniler Paralyse und bei Tumoren und Bielschowsky ist geneigt, in diesen Kugelbildungen eine Widerstandsreaktion zu erbiicken, welche sich dann entwickelt, wenn sich die biologischen Bedingungen für den Bestand des Achsenzylinders durch sklerosierende Vorgänge an einer gegebenen Stelle des zentralen Nervensystems verändern. Bielschows k y legt ferner großes Gewicht auf atypische Axon- und Kollateralbildungen in der Hirnrinde der spätinfantilen Form der amaurotischen Idiotie. Besonders die Purkinje-Axonen zeigen häufig Axonanschwellungen (wie dies E. Frey und i $\mathrm{ch}$ bereits im Jahre 1913 nachwiesen); hier legt sich Bielschows $k y$ wohl die Möglichkeit einer Degenerationserscheinung vor, doch widersprächen ,eindeutige Sprossungsphänomene“, indem an den Schwellungspolen sich Kollateralen entwickeln. „Es kann bei der fast gesetzmäßigen Wiederkehr dieser Bilder gar keinem Zweifel unterliegen, daß hier ein atypisches Wachstumsphänomen vorliegt" (S. 187 1. c.). Endlich: „Man kann sich das Zustandekommen der Axonschwellungen kaum anders vorstellen, daß die von Neuroblasten gelieferte und von ihm abströmende Substanz in den Plasmodesmen der Körnerschicht auf einen Widerstand stößt, daß sie sich an der Stelle des Hindernisses zunächst zu einer Kugel anstaut, sich aber dann durch die Bildung von Seitensprossen Ventile schafft" (S. 187 l. c.).

Diesen Ausführungen Bielschowskys möchte ich folgende Bemerkungen entgegenhalten : 1. Da erfahrungsgemä $B$ die Axonschwellung der Purkinjeschen Zelle an Abzweigungsstellen von Kollateralen auftritt, so ist die Möglichkeit gegeben, Sprossungsphänomene mit normalen Kollateralen zu identifizieren. Somit ist auch die, gesetzmäßige Wiederkehr" verständlich, da doch die Sprossungen auf normalen Abzweigungen beruhen. 2. Mit einer Sprossungstendenz sind die Verlaufsanschwellungen schwer zu vereinen, denn die Regeneration gibt sich doch in den typischen End kugeln kund. 3. Ein wichtiges Gegenargument ist die Tatsache, daß bei der infantil-amaurotischen Idiotie sich ein gewaltiger, weil auf das gesamte zentrale Nervensystem erstreckender Absterbungsprozeß abspielt, mit welchem sich Sprossungsphänomene als positive Lebensäußerungen nicht vereinen lassen. Wie einseitig Bielschowsky diese "Sprossungen" deutet, ergibt sich aus jener Äußerung, wonach er selbst die bei juveniler Paralyse in der Kleinhirnrinde gefundenen Kugeln als Erscheinungen eines Regenerations- 
prozesses annimmt! Immerhin bleibt es einer mehr-minder individuellen Appreziation überlassen, ob man in der Kleinhirnrinde bei Ta y - Sachs reichlichere Kollateralbildungen erblickt; in diesem Fall kann man diese vielmehr als fötale Bildungsremanenzen betrachten, die infolge der Arretierung des Entwicklungsvorgangs durch die vorzeitige Erschöpfung bewirkt sein könnten. Jedenfalls ist es kaum angängig einem in höchstgradiger Erkrankung befindlichen Zentralorgan normale Bildungstendenz zuzuschreiben und meinerseits konnte ich in den ron Doinikow und Bielschowsky in der Nachbarschaft von Tumoren und bei multipler Sklerose gefundenen Axonschwellungen immer nur Degenerationsphänomene erblicken!

Nach obigem schließe ich folgend: Der Axon schwillt bei der infantil-amaurotischen Idiotie besonders im Kleinhirn und Rückenmark ebenso primär-degenerativ an wie der Nervenzelleib und die Dendriten; diese Axonschwellung bildet einen integrierenden Punkt des pathohistologischen Geschehens und somit entfällt die von mir 1909 statuierte A utonomie des Axons; letztere war mehr ein Notbehelf, mit welchem ich die scheinbar gesetzmäßige Verschontheit des Nervenleiters begreiflich machen mich bestrebte und womit ich mich vor einem scheinbaren Faktum zu beugen gezwungen fühlte. Wie konnte ich auch anders handeln, da 10 Fälle dasselbe, nämlich die Integrität des Axons lehrten, worauf der 11. Fall folgte, in welchem mir die ersten Axonschwellungen zu Gesicht kamen und die ich nun in weiteren 2 Fällen antraf; ich wäre heute sehr geneigt anzunehmen, daß für die ersteren Fälle - allerdings für eine gewisse Anzahl - eine aufmerksame Nachforschung Andeutungen hinsichtlich Axonschwellungen ergeben könnten. Doch will ich diese subjektive Vermutung, mit welcher nichts bewiesen wird, ganz ausschalten und begnüge mich bei Deutung etwaiger Differenzen in bezug der Axonschwellungen mit dem zuletzt auch von Biels chows ky betonten. Umstand, daß fast jeder Fall von infantil-amaurotischer Idiotie in seinem anatomischen Substrat eine eigene Note hat.

Meine Bemerkungen über die degenerativen Axonschwellungen möchte ich mit einem Hinweis auf die experimentellen Erfahrungen Cajals und die Befunde von H. Spatz beschließen, welche einwandfrei die sich auf traumatische Eingriffe entwickelnde degenerative Blähung so der Nervenzelle wie des zentralen Axonstumpfes klarlegten. Namentlich erfuhren wir aus der experimentellen Forschung des spanischen Autors, daß auf Quertrennungen zentraler Nervensubstanz im proximalen Neuronstumpf ballonförmige Blähungen des Axons entstehen, die bis zur geschwellten Ursprungszelle zu verfolgen waren. Diese kugeligen Auftreibungen des Axons betrachtete Cajal als die frühzeitige Manifestation der traumatischen Degeneration, welche 
in der Nähe des Eingriffs rasch verschwinden, sich hingegen von diesem entfernter also zur Ursprungszelle näher überraschend lang halten. Das Silberbild solcher Blähungsstellen zeigt aufgelockerte „Fibrillen“, die hier ein Netzwerk bilden. Es handelt sich nach H. S patz ) um die Schwellung des strukturlosen Hyaloplasmas, die das fibrilläre Netzwerk übertrieben zur Darstellung bringt. Solche Stellen sind nach H. S patz bei Nissl-Färbung ungefärbt, bei Säurefuchsin- und Eosinfärbung homogen rosarot, bei Alzheimers Fuchsinlichtgrünfärbung erscheinen die geschwellten Stellen mit fuchsinophilen Granulis vollgepfropft. Es ist nun eine ebenso wichtige als interessante Tatsache, daß im zentralen Neuronstumpf die Schwellungen des Achsenzylinders und der Ursprungszelle zeitlich zusammenfällt und somit sich beide Teile als zusammengehörig erweisen. Und so reagiert der Axon ebenso als die Nervenzelle, daher kann man nicht allein im Sinne Niss Is von einer ,primären Reizung" der Nervenzelle, sondern auch von einer „,primären Veränderung" der Nervenfaser (H. S patz) sprechen. Im zentralen Stumpf verhalten sich Ursprungszelle und Axon wie ein Stück, dessen Reaktionsgrad vom Orte der Läsion abhängt, denn liegt die Läsionsstelle weit entfernt, so muß die Nervenzelle nicht unbedingt anschwellen, hingegen schwillt diese um so mehr an, je näher zu ihr der Eingriff und je brüsker dieser geschah. Diese Veränderungen des zentralen Stumpfes vergleicht S patz mit einer Welle, welche sich von der Läsionsstelle aus ein Stück weit je nach der Stärke des Reizes fortpflanzt und die Zelle nur dann angreift, wenn der Reiz stark genug war und wenn die Zelle nicht zu entfernt vom Ausgangspunkt der Welle lag.

H. Spatz betrachtet die auf Neurontrennung erscheinenden Auftreibungen des zentralen Axonstumpfs samt Blähung der Nervenzelle als Phänomene, die aus der Schwellung des undifferenzierten Protoplasmas, des Hyaloplasmas, resultieren; sie sollen noch keine Degenerationserscheinungen vielmehr die Reaktion des lebenskräftigen Protoplasmas darstellen. Was uns hier im Zusammenhang mit den Blähungen des Neurons bei amaurotischer Idiotie interessiert, ist die Tatsache, daß bei einem mechanischen Eingriff gegen die Neuronintegrität so die Ursprungszelle samt Dendriten wie der Axon sich gleichmäßig verändern; und so kann für einen so einförmigen und alles pathologische Geschehen derartig beherrschenden Proze 3 wie der degenerative bei der familiären Idiotie auch nur gefolgert werden, daß diesen Zelle wie Axon - weil gleichzeitig und gleichartig - in identischer Weise erleiden. Dem Axon eine Sonderstellung einräumen hatte nur so lange eine

1) Spatz, Hugo, Über die Vorgänge nach experimenteller Rückenmarksdurchtrennung mit besonderer Berücksichtigung der Unterschiede der Reaktionsweise des reifen und unreifen Gewebes. Nissl-Alzheimersche Arbeiten 1921. 
gewisse Berechtigung, bis man diesen für intakt wußte; sobald aber an diesem gleichfalls lokale Schwellungen nack gewiesen wurden, konnten diese nicht anders als jene der Dendriten und des Zelleibs aufgefaßt werden. Denn es ist schwer zu begreifen, warum bei einem derartig einheitlich-degenerativen ProzeB noch das Walten eines zweiten Prinzips, das obendrein biologisch so gegensätzlich zur Degeneration wie die Regeneration ist, anzunet men wäre.

Vergleichen wir die Schwellungen des Axons mit jenen der Dendriten und Nervenzellen, so fällt auf den ersten Biick die relative Spärlichkeit ersterer gø gøn letztere auf. Dieser Umstand dürfte seine zwanglose Erklärung in der bekannten histopatkologiscten Resistenz des Axons finden, wonach von den Neuronbestandteilen zuerst das Myelin, hernach die Nervenzelle samt Dendriten leiden und so kommt es besonders bei chroniscten Prozessen vor, daß marklose Axone aus höchstgradig veränderten Zelleibern ihren Ursprung nehmen können. Erst später, d. h. nach völligem Untergang, der Nervenzelle schwindet auch der Axon. Diesem Verhalten entspreckend sieht man bei der amaurotischen Idiotie Axonschwellungen, die, wie oben bemerkt, allein fuchsinophile Körner aufweisen, hingegen gelang mir bisher an keiner Stelle lecithinoide oder lipoide Körnelung nachzuweisen. Hieraus dürfte auf die viel spätere Entstehung der Axonschwellungen gefolgert werden, denn die späteren Schwellungen enthalten jüngere bzw. primitivere Degenerationsprodukte.

\section{B. Hypothetisches.}

Die Histopathologie der amaurotischen Idiotie war von jeher zur Aufstellung von Hypothesen verlockend. Handelt es sich doch um einen materiellen ProzeB, der ungemein scharf gezeichnet, uns die Veränderungen vermöge seines relativ raschen Abklingens teilweise noch in der Entstehung vorführt, daher auf das histopathologische Geschehen überraschende Streiflichter wirft. Obendrein ist der Prozeß von der denkbar reinsten Endogenität, bietet daher einen ideal-eindeutigen Stoff zur Erschließung des anatomischen Wesens der Heredodegeneration, worüber ich im 8. Band des Schweizer Archivs für Neurologie und Psychiatrie berichtete. Kein Wunder, wenn mich bereits 1913 das damals noch spärliche Material zu allgemeinen Betrachtungen verlockte; noch begreiflicher ist es, $\mathrm{da} B$ ein so gedankenreicher Histopathologe wie $\mathrm{Ma} \times \mathrm{Biel}$ schowsk y auf Grund eines größeren und heute bereits mehr-minder durchgearbeiteten Materials in seiner zusammenfassenden Arbeit über die amaurotische Idiotie pathogenetische Betrachtungen anzustellen sich veranlaßt fühlte, die ihn sogar zu therapeutischen Vorschlägen verführten. Da ich mich in meiner letzten Arbeit (1919) mit den hypothetischen Ausführungen der Savinis und 
von Benders bereits beschäftigt babe, eräbrigt es sich hier nur Bielschowsky Konstruktionen vorzuführen und dieselben kritisch zu beleuchten.

Als Ausgangspunkt diente Bielschowsk y (1. c.) die Annahme einer Schädigung seitens der trophischen Funktion der Glia, die zur Störung im Markaufbau und beim Lipoidstoffwechsel führe. Diese trophische Insuffizienz soll durch ein morphologisches Substrat gestützt sein, dessen einzelne Faktoren wären: 1. Das grobbalkige und lückenhafte Gধfüge der sog. Giundsubstanz der Hirnrinde; 2. Zerfallsprozesse vornehmlich der dritten Schicht der Großhirnrinde, die in Fällen von BieI schowskys spätinfantiler amaurotischer Idiotie zu einem hierortigen spongiösen Schwund führen; 3. Auftreten von großen Gliazellen mit Riesєnkern€n, derєn fast gesetzmäßiges Erscheinen bei der infantilamaurotischer Idiotie einem die Vermutung nahelegt, daß es sich um eine metaplastische Wachstumsrichtung der Glia handle. Dies vorausgeschickt frägt sich Bielschowsky, woher die in den Nervenzellen eingelagerten Substanz€n stammen, die doch das wesentliche histopathologische Kєnnzeichєn des Prozesses ausmachen. Da als „unumstößliches" und „,wesentliches" Krankheitsmerkmal nur die Ganglienzellveränderung übrigbleibt und der zweifellos endogene Defekt in der Zelle zu suchen ist, so ist auch der Fehler in deren vitalen Mechanismus zu vermuten. Welcher Natur wäre nur dieser Fehler? Nach Bielschowsky dient als Fingerzeig jene markante Erscheinung, wonach der Axon intakt bleibt, auch dann, wenn von der Nervenzelle nur mehr Reste übrigbleiben: „,Das Persistieren des Achsenzylinders, an đem sich trotz schwerer Veränderungen seiner Ursprungszelle sogar noch eine lebhafte plastische Energie durch Sprossenbildung bemerkbar machen kann, spricht entschieden dafür, daB diejenige Zellbestandsteile, welche der spezifisch-nervösen Funktion dienen, nicht primär erkrankt sein können“ (S. 192 l. c.) und weiter: „Bei unvoreingenommener Betrachtung der Dinge muß man aus der Integrität der Axone unbedingt den Schluß ziehen, daß die der nervösen Funktion der Zelle dienenden Zellbestandteile durch die Erkrankung primär nicht berührt werden; erst dann, wenn der Prozeß einen extremen Grad erreicht hat, leiden auch sie, und dann wird schließlich der Bestand des Achsenzylinders gefährdet" (S. 193 l. c.). Und so gelangt Bielschowsky zu dem Schluß: „Nach meiner Auffassung werden wir durch die histologischen Befunde dazu gedrängt, die primäre Störung im vegetativen Mechanismus zu such€n" (S. 193 l. c.). Insuffizient wäre ein $€$ ng begrenzter Komplex von Zellfunktionen, jene, die den Stoffwechsel regulieren. Die Ursache der Insuffizienz ist in dem Fehlen oder in der Reduktion der für d€n Stoffwechsel der Nervenzellen notwendig€n Fermente zu suchen. Dadurch kommt es zu Störungen beim Lipoidwechsel und so 
stauen sich im Zelleib hydrophile Einlagerungen, die zur Schwellung führen; hierbei spiele die mangelhafte trophische Funktion der Glia die Hauptrolle. Bevor ich zur Besprechung Bielschows k ys Hypothese überginge, sei darauf verwiesen, daß dieser Autor eine seiner Thesen jene, in welcher zwischen vegetativer und nervöser Funktion der Nervenzelle Unterschied gemacht wird - durch folgende Verklausulierung wesentlich einschränkt: ,Natürlich ist eine scharfe Trennung von vegetativer und spezifischer Zellfunktion nur in der Theorie möglich; in Wirklichkeit stehen beide in engen Wechselbeziehungen, deshalb ist auch die hier vorgetragene Anschauung cum grano salis zu nehmen" (S. 194 1. c.). Die Unwahrscheinlichkeit dieser Trennung soll aber durch die klaren materiellen Manifestationen - s. Integrität des Axons - wettgemacht werden, durch welche die Spaltung der nervösen und vegetativen Funktionen bewiesen werden sollen.

Wenden wir uns nun der Besprechung obiger Hypothese zu, so wäre in erster Linie darauf zu verweisen, daß die Grundlage derselben durch Tatsachenmaterial bei weitem nicht gesichert erscheint. Das grobbalkige und lückenhafte Gefüge der Glia ist ja auch bei anderen Veränderungen der Großhirnrinde anzutreffen, ganz abgesehen davon, daß deren Bedeutung keineswegs als eindeutig zu erachten wäre; der spongiöse Schwund der dritten Rindenschicht ist, soweit ich unterrichtet bin, ein Befund überwiegend der spätinfantilen Form und dürfte ebenfalls nicht überschätzt werden; endlich die großen Gliazellen mit. Riesenkernen wären am meisten zu bewerten, falls ihre Bedeutung als ,,metaplastische" Erscheinung zweifellos wäre. Doch sind mir diese großen Gliazellen der infantilen Form aus eigener Erfahrung sehr gut bekannt, da ich sie zuerst bei Ta y - Sa ch s schilderte; ich identifiziere diese schlankweg mit den Monstergliazellen, wie sie etwa in der Nähe von Erweichungen, an Stellen von durch Gewebszerfall gegebenen Reiz (z. B. auch bei seniler Demenz) massenhaft vorkommen. Ein solcher pathologischer Reiz ist nun bei dem gewaltigen Absterben von Nervengewebe der infantilen Form genügend gegeben; doch denke ich nicht allein an diesen, sondern vielmehr und in erster Linie an die sog. Eigenerkrankung der protoplasmatischen Astrocyten, welche ich in der Form mächtiger Zelleib- und Dendritenanschwellungen beschrieb. Wie ich dies a. a. O. (1919) auseinandersetzte, erscheint bei der infantilamaurotischen Idiotie alles Ektodermale, also auch das Gliagewebe primär degenerativ schwer erkrankt, wie dies heute auch Bielschows ky freilich in seiner eigenen Formulierung erklärt: „Im physio-patbologischen Sinne ist also der Proze $ß$ der amaurotischen Idiotie als Ausdruck der vegetativen Insuffizienz der Ganglienzellen bzw. aller vom Ektoderm. abstammenden Zellen des Z $\epsilon$ ntralnervensystems zu definieren" (S. 196 1. c.). - Auf Grund dieser richtigstellenden Bemerkungen erscheint 
mir das materielle Substrat einer trophischen Insuffizienz durch Bielschowsky nicht erwiesen; ein solches Fundament, wie das von Bielschowsky gegebene, ist für eine darauf fußende Konstruktion entschieden insuffizient.

Und nun zur eigentlichen Hypothese angekommen hebe ich nochmals hervor, daß Bielschowsky selbst die Trennung in nervöse und vegetative Funktion nur in der Theorie für möglich hält, mit anderen Worten, tatsächlich gibt es eine solche Trennung nicht. Da es sich aber um eine Hypothese handelt, so wäre hierauf einzugehen, doch stoßen wir uns dabei sofort an das grundlegende Argument Bielschowskys, wonach das anfängliche Freibleiben der rein-nervösen Zellfunktion durch die Intaktheit des Axons bewiesen würde. Ganz abgesehen davon, daß für die normale Funktion nicht allein der intakte Axon, sondern in erster Linie die normale Nervenzelle bürgt, denn ersterer ist nur der einfache Reizleiter, während letztere der Reizproduzent, so schildert Bielschowsky selbst, speziell für das Kleinhirn Axonschwellungen, bricht aber die Spitze hinsichtlich deren pathologischer Bedeutung dadurch $a b, d a ß$ er diese durch eine gesteigerte plastische Tätigkeit entstanden gedacht, als Überschußbildungen bezeichnet. Oben bestrebte ich mich nachzuweisen, daß seitens der familiär-amaurotischen Idiotie alles für eine primär-degenerative und nichts für eine regenerative Tätigkeit spreche und so sind die Axonveränderungen folgerichtig nur als Produkte der krankhaften universellen Schwellung zu deuten. Die relativ spärlichen Axonschwellungen erklären sich durch die bekannte hochgradige Resistenz des Neuronleiters. Unter solchen Umständen erweist sich auch jener Grundpfeiler der Bielschowskyschen Hypothese für tragunfähig, der zugunsten einer Affektion der vegetativen Funktion nebst anfänglichen Ungestörtseins der reinnervösen Funkition verwertbar wäre; überhaupt erscheint diese Trennung nicht nur eine künstliche, sondern auch eine irreale. Eine vegetativ verminderte Zelle ist zugleich nervös-funktionell vermindert.

Aus obiger Besprechung hebe ich als wesentlich hervor, daß die Glia und das Nervengewebe auf gleicher Grundlage gleichzeitig krank sind; den Ausgang der Nervenzellerkrankung in eine trophisch-insuffiziente Glia zu verlegen, ist ein Vorgang, der durch pathohistologische Tatsachen nicht gestützt wird. Meines Erachtens handelt es sich um eine primäre Degeneration vor allem Ektodermalen; diese Feststellung dürfte heute schon auf keinen Widerstand stoßen. Diese Degeneration. nimmt ihren Ursprung aus einem endogenen Zelldefekt; das Wesen der Heredodegeneration birgt eine solche Annahme in sich. Nun sehen wir aus den pathohistologischen Bildern der infantil-amaurotischen Idiotie, daß diese Degeneration anfänglich mit dem undifferenzierten Protoplasma engstens verbunden ist, so daß man die spezifisch-charak- 
teristischen Degenerationsprodukte allein aus dem Hyaloplasma ableiten kann. Unter solchen Umständen ist es schwer verständlich, wenn Spielmeyer und Bielschowsky die "Hyaloplasmatheorie“ bekämpfen. S pielme yer betont, daß wenn man sich nur an das hält, was man tatsächlich also morphologisch sieht, so sind allein die abnormen Zelleinlagerungen mit ihren Folgen zu beweisen. Ich verschweige nicht, daß angesichts der allörtlichen lecithinoiden Anschoppung der Nervenzellen mich vor ganz kurzem dieser Ausspruch Spielme yers in dem Sinne beeinflußte, daß ich die Auftreibungen bei Ta y-Sachs durch die Degenerationsprodukte bewirkt betrachtete (s. meine „Beiträge zur cerebellaren Heredodegeneration"i, Journ. f. Psychol. u. Neurol. 27, 1921). Doch ergab die obige eingehende Analyse der Präparate die Tatsache, daß es Auftreibungen ohne färberisch nachweisbare Körner gibt und erst aus dieser, auf der Quellung des Hyaloplasmas beruhenden Phase der Zellerkrankung entwickeln sich die abnormen Körner. - Auch Bielschowsky sträubt sich im Hyaloplasma den Träger der Heredodegeneration zu erblicken und hebt den prinzipiellen Gesichtspunkt hervor, ,daß wir in der Ergründung der Pathogenese kaum gefördert werden, wenn wir von so anfechtbaren physiologischen und biologischen Hypothesen ausgehen. Wir müssen uns an das Tatsächliche halten und denjenigen Befund zur Grundlage unserer Betrachtungen wählen, welcher bei allen Formen derselben Krankheit mit gesetzmäßiger Regelmäßigkeit wiederkehrt. Das ist im vorliegenden Falle die Lipoidanhäufung in den Gangleinzellen, sie ist als das Wesentliche der Erkrankung anzusprechen. Die Schwellung ist kein notwendiges Attribut der Zelldegeneration, denn bei der juvenilen Form ist die abnorme Lipoidaufspeicherung als einziges Krankheitszeichen nicht allzu selten... Demnach kann man die Schwellung nur als eine von bestimmten, aber nicht integrierenden Bedingungen abhängige Begleiterscheinung des Grundprozesses gelten (S. 177 1. c.).

Soweit ich auf Grund eigener Erfahrung über infantil-amaurotische Idiotie und vermöge von Kenntnissen der einschlägigen Literatur über die juvenile Form unterrichtet bin, handelt es sich hier bei der familiären Idiotie im weitesten Sinne gemäß den Feststellungen von F. K. Walter gerade um einen Schwellungsprozeß, nur ist dieser im großen und ganzen bei der akut verlaufenden infantilen Form ausgeprägter, daher sinnfälliger. Daß bei der auf 10 und mehrere Jahre sich erstreckenden juvenilen Form Nervenzellexemplare erscheinen, die statt gebläht $\mathrm{zu}$ sein, mehr-minder atropbisch sind, wird keinen Kenner des Prozesses überrasclen: die anfänglich geschwellte Nervenzelle kollabiert bzw. atrophiert mit der Zeit, denn die Degenerationsprodukte machen eine Metamorphose durch, die an und für sich eine Verminderung des Zellvolumens nach sich zieht. Hervorheben möchte 
ich die Tatsache, daß man im Kleinhirn der infantilen Form oft den normalen Dimensionen gegenüber kollabierte Purkinjesche Nervenzellen sieht und selbst im Vorderhorn des Rückenmarks gehört dies nicht zur größten Seltenheit. Es hiє Be aber das Tatsächliche wie auch das Beherrschende des histologischen Bildes zu verkennen, wollte man die Schwellung im histopathologischen Prozesse der familiären Idiotie im weitesten Sinne als etwas Nebensächliches betrachten, dies um so mehr, da bereits vor der Ansammlung von Degenerationskörnern das krankhaft gequollene Hyaloplasma jener Faktor ist, der urs pr ünglich die Schwellung hervorruft.

Hier sei mir gestattet mit Nachdruck zu bemerken, daß ich die Schwellung der Nervenzellen nie als etwas Primäres auffaßte, sondern immer als eine durch intracelluläre Dehnung bewirkte sekundäre Erscheinung schilderte; selbstverständlich sind also die Deformationen an den Nervenzellen keine Wesenszeichen, wie denn ich diese immer nur als sinnfällige Zeichen der morphologischen Schilderung zugrunde legte. Freilich war die durch Einlagerungen bewirkte Deformation bei der juvenilen Form deutlich als solche zu demonstrieren, denn die Einlagerungen als Pigmentmasse machte sich so am Nißl-wie Bielschowsky-Präparate gleich leicht erkennbar. Anders bei der infantilamaurotischen Idiotie, bei welcher die erste histologisch nachweisbare Spur der protoplasmatischen Degeneration in einer vergrößerten und durch das Fuchsin angehaucht färbbaren gallertigen protoplasmatischen Masse gegeben ist, die gegen das Lipochrom förmlich ein€n embryonalen Entartungsstoff darstellt. In dieser ganz beginnenden Form der intracellulären Degeneration kommt eine durch Quellung bedingte abnorme Volumenzunahme des Hyaloplasmas - morphologisch gesprochen: Hypertrophie - zum Ausdruck; erst später entwickeln sich die mit Fuchsin intensiver gefärbten kugeligen Fällungen der wabig-fibrillären Netzlücken, aus welchen zunehmend semilecithinoide, dann mit Weiger ts Hämatoxylin intensiv färbbare lecithinoide, später prälipoide, zuletzt lipoide Körner werden, die, endlich osmioreduktiv werdend, eine neutralfettige Endphase erreichen können. Wenn somit Bielschowsky behauptet, daß die Schwellung kein notwendiges Attribut der Zelldegeneration sei, sondern nur eine von bestimmten, doch nicht integrierẹnden Bedingungen abhängige Begleiterscheinung, so muß ich diese Auffassung als eine den tatsächlichen, durch das Mikroskop demonstrierten Verhältnissen widersprechende ablehnen. Oben wies ich nach, daß die körnerlose Quellungsphase der körnigen Fällungsphase vorangeht, worauf die hochgradigen Blähungen ołne die geringste Spur von lecithinoiden Körnern deutet; entwickeln sich im ferneren Verlauf die körnigen Degenerationsprodukte, so nehmen sie natürlich den durch die Schwellung aufgetriebenen Bezirk des Zelleibs bzw. der Dendriten ein, und 
täusch€n somit die Sckwellung auf Grund von Anschoppung mit lecithinoiden Körnern vor. So mit ist die Schwellung keine Be gleit-, sondern eine Integralerscheinung in dem Sinne, daß die Auftreibungen der Nervenzellen, Dendriten und Axonen durch eine primäre, in Quellung sich äußernde Veränderung des Hyaloplasmas bedingt werden; dies ist eine Tatsache und keine ,anfechtbare Hypothese ${ }^{‘ \text {. }}$. Erst alles übrige ist eine mehr oder minder gefällige Konstruktion mit mehr oder minder plausibler Begründung, an welche gar therapeutische Vorschläge zu knüpfen zumindest verfıüht erscheint.

\section{c. Anlagezeichen bei der infantil-amaurotischen Idiotie.}

Bekanntlich vertrat ich in meiner zusammenfassenden Arbeit ${ }^{1}$ ) den Standpunkt, daß in Fällen von echter Sachsscher familiär-amaurotischer Idiotie das Zentralorgan weder tektonische Anomalien von Belang, noch pattologisch-anatomische Prozesse von Bedeutung aufweise. In der äußeren Konfiguration $\mathrm{kob}$ ich als ,,untergeordnete Abweichung" die in zwei Fällen klaffende Sylviussche Spalte hervor, wodurch eine kleine Stelle der Insel aus der Tiefe frei sichtbar wurde. Grob makroskopische Veränderungen schloß ich für die infantile Form der familiären Idiotie aus, wobei natürlich akzidentelle Veränderung€n, die also zu dem grundlegenden Proze $\beta$ in keinem engeren Verhältnis steb€n, wohl vorkommen könnєn.

Schon aller Anfangs stand die Frage im Vordergrund, ob Anlagezeichen bei einer so eminent-€ndogen€n Krankheit wie die infantilamaurotische Idiotie, nicht vorkommen? Als ich dann 1919 in einem Fall die Tektonik vermöge der sehr distinkten, lecithinoiden Degeneration der Nervenzellen mittels Weigerts Markscheidenfärbung g€nau verfolgen konnte, fiel mir auf Grund K. Brod manns maßgebenden Bestimmungen der Umstand lebhaft auf, daß so die Area gigantopyramidalis wie striata ein tierähnliches Verhalten bekunden, wodurch das anatomische Substrat als ein minderwertiges erschien. Diese Auffassung wurde durch 0 . und C. Vogt²) mit aller Entschiedenheit zur ückgewiesen mit dem Hinweis, daß die von Brod man $n$ behaupteten pitkekoiden Grenzverschiebungen zwischen vorderer und hinterer Zentralwindung auch für den Menschen gültig sind, namentlich daß das Ùbergreifen des granulären Postzentraitypus auf das orale agranuläre Labium der $Z_{\epsilon}$ ntralfurche eine vollkommen normale Erscheinung

1) Schaffer, Karl, Über die Anatomie u. Klinik der Tay-Sachsschen amaurot.fam. Idiotie mit Rücksicht auf verwandte Formen. Zeitschr. f. die Erforsch. d. jugendl. Schwachsinns, 3. 1909.

2) Oskar und Cécile Vogt, Allgemeinere Ergebnisse unserer Hirnforschung. Journ. f. Psychol. u. Neurol. 25, Erg. 1. 
sei. Was nun hinsichtlich der Area striata Vogts betonen, daß nämlich die Ausdehnung auf $\mathrm{O}_{2}$ beim Menschen auch typisch sei, ist ja richtig, damit berühren sie aber nicht jene Feststellung, die in der Ausdehnung auf die ganze Lingualiswindung bei Ta $\mathrm{y}$ - Sachs besteht und welche ich mit Bezugnahme auf Brodmanns Forschungen für pithekoid bezeichnete. - Die für die Calcarinarinde von mir angegebene Überdifferenzierung in zehn Schichten vermögen Vogts, aus den ungenügenden Abbildungen Schaffer s" nicht zu ersehen. Vogts leiten ihre Ablehnung mit folgenden Worten ein: „Nichts kann die Anerkennung der wissenschaftlichen Bedeutung der Arckitektonik mehr verlangsamen, als wenn irrige Behauptungen oder Anschauungen auf ibrem Gebiete von anderen Autoren aufgegriffen und zu Bausteinen weitgehender Hypothesen benutzt werden." Und gleich weiter: "Wir hatten gehofft, nicht glückliche Behauptungen, Deutungen und $\mathrm{Zu}$ sammenfassungen Brodmanns und Kölpins durch gelegentliche Bemerkungen korrigieren zu können. Aber das Vorgehen Schaffers zwingt uns zu einer eingehenderen Kritik" (l. c.).

Hierauf habe ich kurz folgendes zu bemerken. Auch ich teile vollinhaltlich den selbstverständlichen Ausspruch, daß man auf irrige Behauptungen nicht baue. Doch wie konnte in mir hinsichtlich der Vollgültigkeit der Brodmannschen Sätze auch nur der leiseste Zweifel aufsteigen, da diese seit 1906, also 13 Jahre hindurch - mein inkriminierter Aufsatz erschien 1919 - ohne Widerspruch bestanden? Wir können Vogts sicherlich nur dankbar sein, daß sie auf etwaige Irrtümer Brod manns aufmerksam machen und dadurch einem weiteren Eingang unrichtiger Auffassungen vorbeugen. Schade nur, daß dies nicht früher geschah, zu einer Zeit, da auch Brod mann in der Lage gewesen wäre, seine Lehre zu verteidigen; gemäß der heutigen Sachlage steht Behauptung gegen Behauptung, und somit kann das Problem noch als strittig betrachtet werden. Und da würde ich mir die Frage gestatten, ob pithekoide Zeichen einfach dadurch, weil sie im Normalgehirn vorkommen, ihren Wert als Stigmen niederer Organisation verlieren? Mit dem Hinweis, daß bei Affen vorkommende Struktureigenheiten auch im menschlichen Normalgehirn vorkommen, ist die pithekoide Natur derselben keineswegs widerlegt, vorausgesetzt, daß beim Menschen dasselbe Strukturdetail in vielen Fällen in abweichender, beim Affen nicht vorkommender Form anzutreffen ist. In solchen Fällen handelt es sich um eine pithekoide Variante, die als solche eine morphologische Minderwertigkeit darstellt, da doch das für den Menschen Charakteristische nicht erreicht wurde. Kann doch ein im übrigen normaler Mensch Morelsche Ohren haben, und es fiele uns nicht ein, deshalb die pathologische Dignität dieses degenerativen Zeichens zu leugnen. 
Mit obigen Bemerkungen will ich nicht den Schein wecken, als würde ich die pithekoide Mikromorphologie der Tay-Sachsschen Gehirne für gesichert erachten, denn dazu bedarf es noch allzusehr der ferneren Forschungen; hierauf deutet folgender Satz meiner angefochtenen Arbeit ${ }^{1}$ : „Bewahrheitet sich die für einen Fall von Tay-Sachs nachgewiesene Tierähnlichkeit bezüglich der Cytotektonik der homogenetischen Großhirnrinde im allgemeinen, so wäre das Zentralorgan der fraglichen Krankheit als ein mikromorphologisch minderwertiges $\mathrm{zu}$ bezeichnen mit dem Vorbehalt, $\mathrm{da} B$ von weiteren eingehenden morphologischen Untersuchungen der Großhimoberfläche noch Ergebnisse über Affenähnlichkeit zu erwarten wären." In letzterer Beziehung verwies ich auf die Arbeiten von E. Zuckerkandl, Elliot S mith und K. Brod mann, die in der Form einer occipitalen Operculisation das Homologon der echten Affenspalte nachwiesen. Brodmann konnte dieses Verhalten an Javanergehirnen auffinden und nachweisen, daß auf dieses Operculum occipitale die Area striata sich im Gegensatz zum Europäergehirn erstrecke. Mit Bezugnahme auf obige Arbeiten unterwarf ich das mir zur Verfügung stehende letzte Tay-Sachs-Gehirn einer genauen Prüfung der Großhirnoberfläche, wobei sich eine partielle Operculisation des Occipitallappens ergab. Bei der diesbezüglichen Feststellung hielt ich mich genau an die Mahnung E. Zuckerkandls2), wonach zur Identität einer Furche mit der Affenspalte am Affengehirn gehören: 1. Tieflage der Übergangswindungen aus $\mathrm{O}_{2}$ und $\mathrm{O}_{3}$ und 2. Gedecktsein derselben durch das Operculum occipitale bis zur Berührung des letzteren mit dem Gyrus angularis. Liegen daher die Übergangswindungen aus $\mathrm{O}_{2}$ und $\mathrm{O}_{3}$ oberflächlich, so erscheint die der Affenspalte entsprechende, gegen die Angularis halbmondkonvexe Furche - Sulcus lunatus s. simialis - aufgelöst, wie dies nach E. Zuckerkandl für die Mehrzahl der menschlichen Gehirne zutrifft, denn bei letzteren ist nur ausnahmsweise die Reduktion der Übergangswindungen so weit fortgeschritten, daß das Operculum occipitale unmittelbar an den Angularis anschließt.

E. Zuckerkand 1 unterschied am menschlichen Gehirn hinsichtlich des Operculum occipitale folgende Formen:

1. Das Operculum occipitale ist infolge der Tieflage der aus $\mathrm{O}_{2}$ ausgehenden Ứbergangswindung mit dem Angularis in Berührung.

2. Das Operculum occipitale berührt den Angularis nicht, da es durch die zweite UUbergangswindung, von welcher ein Stück oberflächlich liegt, abgedrängt erscheint.

1) Schaffer, Karl, Neue Beitr. z. Mikromorphologie u. anat. Charakterisierung d. inf.-amaur. Idiotie. Zeitschr. f. d. ges. Neurol. u. Psychiatr. 46. 1919.

2) Zuckerkandl, E., Über d. Affenspalte u. das Operculum occipitale des menschl. Gehirns. Obersteiners Arbeiten 12. 
3. Das Operculum occipitale wird durch eine vollkommen freiliegende zweite Übergangswindung vom Angularis geschieden.

4. Das Operculum occipitale schließt an die dritte Übergangswindung an.

5. Das Operculum occipitale erscheint rudimentär.

6. Das Operculum occipitale ist nicht entwickelt.

Von diesen Variationen bedeutet die sub. 1, angeführte die rein pithekoide, die sub 5. und 6 . die rein humane; zwischen diesen zwei

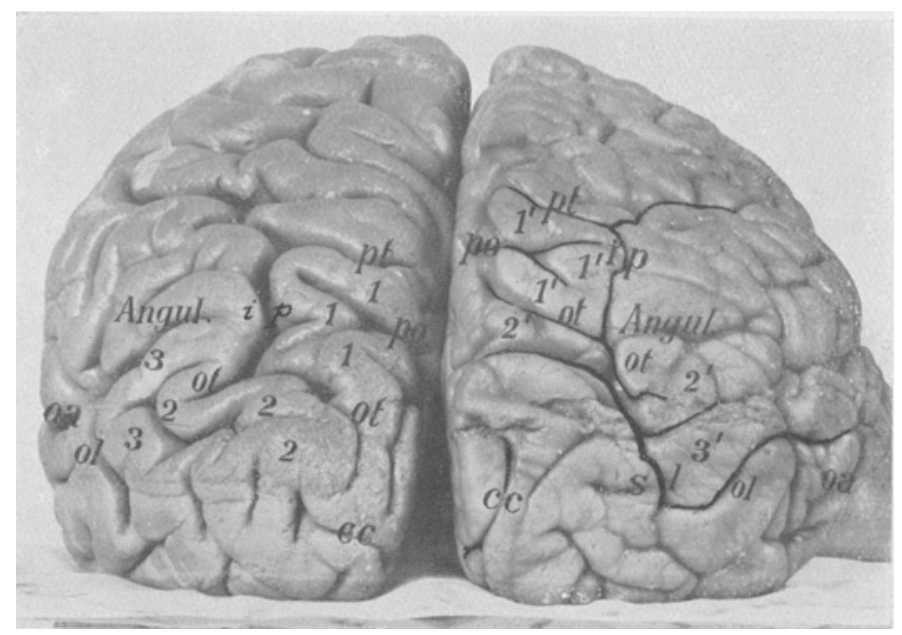

Abb. 8. Affenspaltrest ( $\mathrm{Z} \mathbf{u} \mathrm{ck}$ e $\mathrm{rkand}$ ) eines Falles von $\mathrm{T}$ a $\mathrm{y} \cdot \mathrm{S}$ a c h s im rechten Occipitallappen, neben weichen zum Vergleich ein normaler Occipitallappen gestellt ist. Angul Gyrus angularis; ip Fissura interparietalis; ot Sulcus occipitalis transversus; po Fissura parietooccipitalis; $c c$ Fissura calcarina; $s l$ Sulcus lunatus $s$. simialis; ol sulcus occipitalis lateralis; oa Sulcus occipitalis anterior; $l^{\prime}, l^{\prime}, l^{\prime}$ Erste occipitale Übergangswindung; $2^{\prime}, 2^{\prime}$ Zweite occipitale Übergangswindung; $3^{r}$ Dritte occipitale Übergangswindung bei $\mathbf{T}$ a $\mathrm{y}-\mathrm{S}$ a $\mathrm{ch}$ s. Dasselbe als $1,2,3$ am Normalhirn.

Extremen stellen die übrigen Formen Übergänge dar. Mein Fall entspricht der sub 2. und 3. erwähnten Möglichkeit, wie dies aus Abb. 8 ersichtlich ist, auf welcher die occipitale Ansicht der rechten Hemisphäre von Tay-Sachs auf der rechten Hälfte, während dieselbe Ansicht einer normalen linken Hemisphäre auf der linken Hälfte der Abbildung wiedergegeben ist. Gehen wir von letzterer aus, so ist leicht festzustellen, daß - abgesehen von der mit 1 bezeichneten und die parieto-occipitale Fissur ( $p o$ ) umgehenden ersten Úbergangswindung - die zweite UUbergangswindung (2) um den Sulcus occipitalis transversus (ot) ganz oberflächlich gelegen in den von der Interparietalfissur (ip) auswärtsliegenden Gyrus angularis hineinfließt, wie dies auch für die dritte Übergangswindung (3) nachzuweisen ist. Unterwerfen 
wir nun die Tay-Sachs-Hemisphäre einer gleichörtlichen Besichtigung, so lassen sich folgende Momente feststellen: die erste Ubergangswind ung $\left(l^{\prime}\right)$ windet sich um po genau so wie am Normalhirn; die z weite U'bergangswind ung $\left(2^{\prime}\right)$ zieht unterhalb ot als ein schmaler, lateralwärts zunehmend sich verengeernder Windungszug, der rückwärts durch eine Spalte abgegrenzt wird, die nach vorn konvex-halbmondförmig erscheint und sich abwärts fortsetzend, die dritte Übergangs wind ung (3') durchschneidet. Auf Grund dieser Verhältnisse erkennen

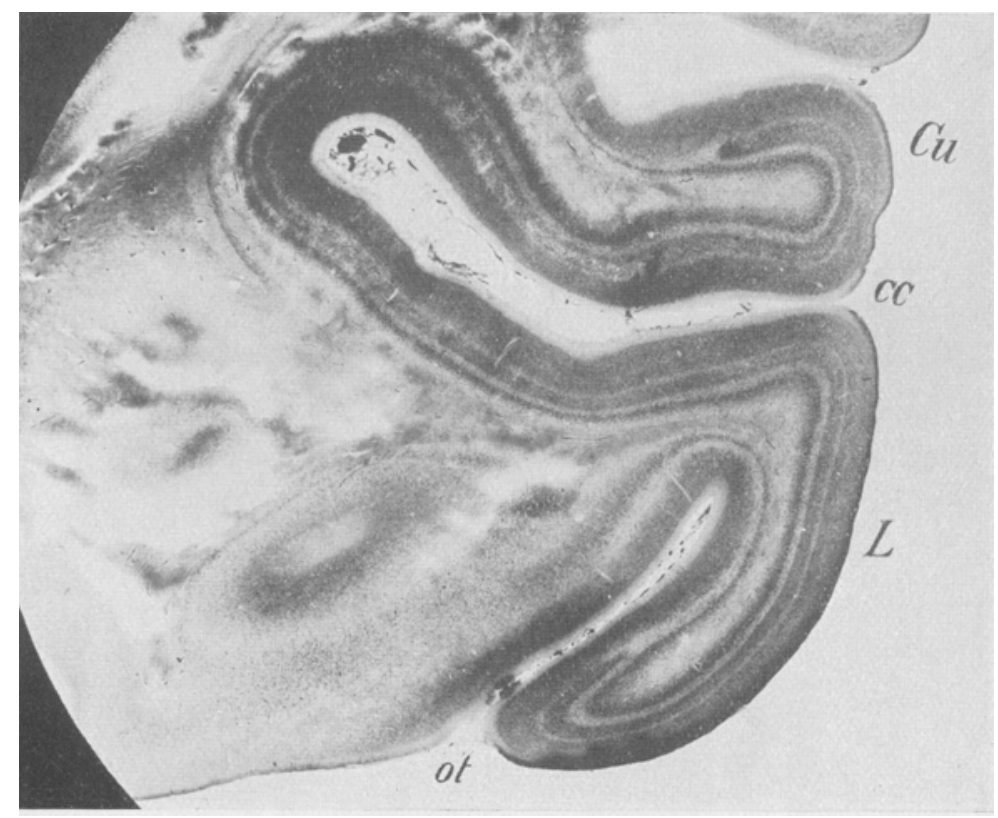

Abb. 9. Area striata meines neuesten Falles von T a $\mathrm{S}-\mathrm{S}$ a $\mathrm{chs}$. Milkroplanaraufnahme eines Weigert-Schnittes in frontaler Richtung. $C u$ Cuneus; $c c$ Fissura calcarina; $L$ Gyrus lingualis; ot Sulcus occipito-temporalis. Bemerkenswert ist die Ausdehnung der Area striata auf die ganze Breite der Lingualiswindung.

wir, daß die Operculisation in diesem Tay-Sachs-Fall eine unvollkommene ist, da die zweite Übergangswindung, obschon reduziert, doch noch zu erkennen ist, und somit stellt die hinter letzterer Windung verlaufende Furche $(s l)$ gemäß Zuckerkandls Auffassung einen Affenspaltrest dar. - Im Anschluß an diese makroskopisch-pithekoide Konfiguration verweise ich auf die Tatsache, daß die Area striata mikroskopisch auch pithekoid infolge der Ausbreitung derselben auf die ganze Breite des Lingualis erschien (s. unten bei Schilderung des Falles auf Abb. 9). 
Mein letzterwähnter Tay-Sachs-Fall bietet noch im Rückenmark ein Zeichen ontogenetischer Retardation dar. Es handelt sich um eine ungewöhnliche Furche des Seitenstrangs in der Höhe der Halsanschwellung, die in dessen dorsalen Rand etwa in der Höhe des Hinterhornhalses nur in die eine Hälfte des Rückenmarks ziemlich tief einschneidet. Diese seitliche Furche dringt in das Areal der markarmen Seitenstrangpyramide $(S P)$ ein und wird durch einen dünnen Marksaum begrenzt, der dorsal und ventral mit der hier breiten Flechsigschen Kleinhirn-

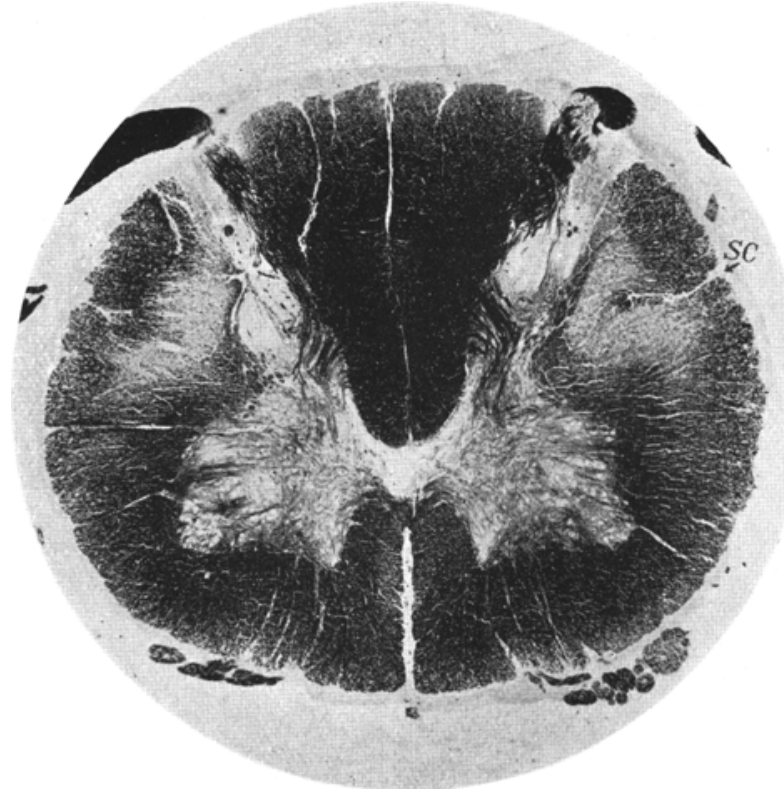

Abb. 10. Querschnitt des Halsmarks meines neuesten Falles von T a - S a c h s. Mikroplanaraufnahme. se Sulcus cylindricus ( $\mathrm{H}$ i s) einseitig.

seitenstrangbahn zusammenfließt (s. Abb. 10). Die andere Rückenmarkshälfte zeigt am Rand des Seitenstrangs eine ähnliche Einkerbung nicht, daker erscheint hier auch das Areal der SP ohne Einschnitt und die KSB als mehr oder minder glatter Saum. Worauf noch aufmerksam zu machen wäre, ist die vollkommene Symmetrie der Vorderstränge, in welcher keine sichere Andeutung einer VP zu bemerken ist.

Die soeben dargestellten Verhältnisse finden eine noch deutlichere Illustration durch das Halsmark eines früheren Falles von Ta y - Sachs (s. Abb. 11), in welchem diese seitliche Rückenmarksfurche bilateral und ungleich tief ist; hervorzuheben ist die Asymmetrie der Vorderstränge, in welchen eine den $V P$ entsprechende Aufhellung nicht zu erkennen ist. 
Diese angedeutete Furche beschäftigte einstens $H$. Obersteiner ${ }^{1}$ ) und seine Schüler; sie dürfte am embryologischen Rückenmark zuerst wohl von Flechsig in seinen Leitungsbahnen geschildert worden sein, der sich wie folgt äußerte: ,In den Seitensträngen findet sich bei Überwiegen der Vorderstrangbahnen in der Regel eine Längsfurche, welche besonders im Halsmark stark ausgeprägt zu sein pflegt. Im oberen Drittel desselben ist sie gewöhnlich zwischen hintere Wurzeln und Kleinhirnseitenstrangbahnen eingeschoben; in der Mitte der Halsanschwellung findet sie sich ungefähr in der Mitte zwischen dem äußersten (seitlichsten) Punkt der Seitenstrangperipherie und der Eintritts-

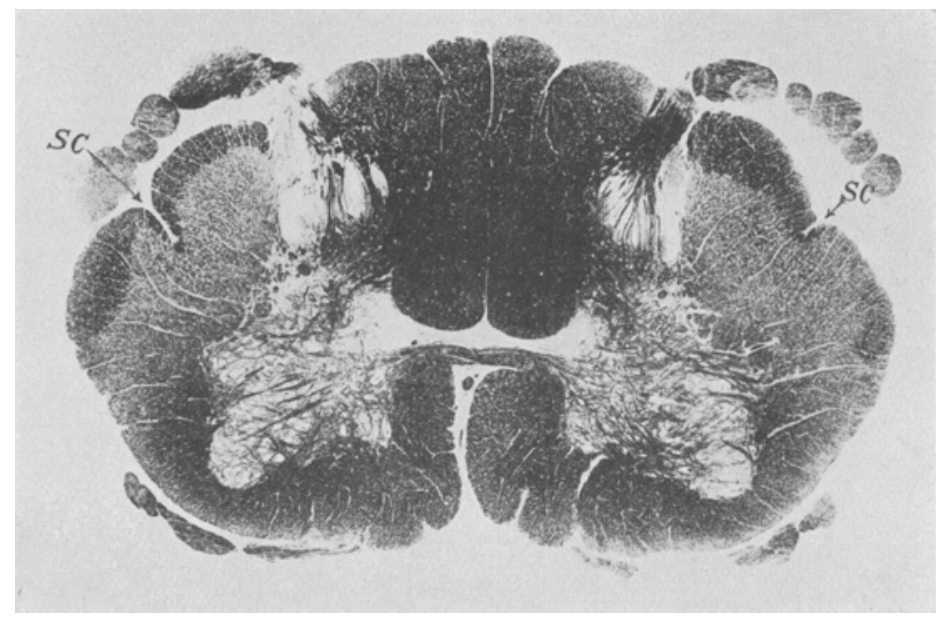

Abb. 11. Querschnitt des Halsmarks eines meiner älteren Fälle von $\mathrm{T}$ a y - S a ch s. Mikroplanaraufnahme. sc Sulcus cylindricus (H is) beiderseitig.

stelle der hinteren Wurzeln. Der Sulcus intermedius anticus sowohl, wie die letztgenannte Furche kann ein- oder beiderseitig auftreten, je nachdem wir es mit einer symmetrischen oder asymmetrischen Verteilungsweise der Pyramidenbahnen zu tun haben." - Gegen diese Flechsigsche Erklärung, welche die Einkerbung des Seitenstrangs mit der kompensatorisch schwachen Entwicklung der SP bei gleichzeitiger Überentwicklung der kontralateralen $V P$ in Zusammenhang bringt, nahm mit vollem Recht Obersteiner Stellung, indem er darauf verwies, daß nicht allein die Unterentwicklung, sondern selbst die vollständige Agenesie der $S P$ nicht dazu genüge, um die fragliche Seiten-

1) Obers t e in e r, H., Nachträgliche Bemerkungen zu den seitlichen Furchen am Rückenmarke. Obersteiners Arbeiten 8. 
furche entstehen zu lassen. Es wäre nämlich darauf aufmerksam zu machen, daß man in Fällen von hochgradigen cerebralen Mißbildungen (Hemi- und Anencephalie, Porencephalie) im Rückenmark wohl diese seitliche Furche sah (Schupfer, Ilberg, Paltauf, Obersteiner, R. Pfeiffer usw.), doch gibt es Fälle, wie von Hitschmann und $Z$ a p pert, wo diese ebenso fehlte, wie in einer anderen Reihe kindlicher Rückenmarke, deren $V P$ ein- oder beiderseitig auffallend groß und $S P$ entsprechend kleiner war (Obersteiner). Diese Beobachtungen kann ich auf Grund identischen Materials (mir standen zu Gebote 2 Fälle von kompletter Anencephalie, mehrerer Hemicephalien, elf foetale Rückenmarke Normaler) vollinhaltlich bestätigen. Sehr richtig kommt somit Obersteiner zum Schluß, daß noch ein Faktor in der Anlage zur Furchenbildung an dieser Stelle der Rückenmarksperipherie eine Rolle spiele; die somit präformierte Furche werde nach ihm aber durch eine Unterentwicklung bzw. sehr frühzeitig eintretende Degeneration der $S P$ wesentlich vertieft.

Nach meinem Dafürhalten spielt in der Ausbildung der seitlichen Rückenmarksfurche einzig und allein die fötale Anlage bzw. deren Aufrechterhaltung auch im postnatalen Leben eine Rolle. Die Furche ist mit der His schen $\mathrm{Z}$ ylind erf u r c he identisch, die bereits im sch wächlichen Seitenstrang eines $4^{1 / 2}$ Wochen alten Embryos vorhanden und gut angedeutet noch im dritten Foetalmonat bemerkbar ist, und zwar genau an jener Stelle, welche am Rückenmark der Ta ySachsschen Fälle als Einkerbungspunkt dient. Dabei ist die fragliche Furche von etwaigen Pyramidenvariationen unabhängig, denn sie bleibt in Fällen von hypoplastischen Seitenpyramiden sehr oft aus. In einem unterentwickelten Zentralorgan, wie bei Hemi- und Anencephalie trifft die hypoplastische Pyramide mit dem Sulcus cylindricus als embryonale Remanenz zusammen, ohne sich gegenseitig zu bedingen.

A us obigen Beobachtungen läßt sich feststellen, daß die Hemisphärenoberfläche bei der infantil-amaurotischen Idiotie pithekoide Gestaltung, ferner das Rückenmark ontogenetische Relikte in der Form des Sulcus cylindricus von His ein-oder zweiseitig a ufweisen kann. Nehmen wir hinzu noch die klaffende Sylviussche Spalte, so müssen wix bekennen, daß Bildungsabweichungen, sei es in Form von Tierähnlichkeit, sei es als fötale Remanenzen, nicht so selten sind. Die infantile Form der familiären Idiotie weist daher Anlagezeichen des zentralen Nervensystems a uf, womit dieses als ein subnormales Organ mor phologisch gekennzeichnet ist. 


\section{Sehilderung eines neuesten Falles von infantil-amaurotischer Idiotie.}

Der Fall war hinsichtlich des Maculabefundes typisch, während bezüglich des Alters eine Verzögerung bestand, da das kleine Mädchen jüdischer Eltern mit 26 Monaten starb, somit um 4 Monate das zweite Lebensjahr, vor welchem bekanntlich der Tod der Ta y-Sachsschen Kranken eintritt, überschritten hat. Man könnte sagen, daß es sich um einen Fall handelte, der zwischen der typischen infantilen und der Bielschowskyschen spätinfantilen Form der amaurotischen Idiotie stand; noch genauer gesagt, war es ein Fall, der dem Dollinger Bielschowskyschen infantilen Fall sehr nahe stand, in welchem es sich um ein Mädchen jüdischer Eltern handelte, dessen Tod im Alter von 2 Jahren and 7 Monaten eintrat, und somit als der bis jetzt am längsten beobachtete Fall von infantil-amaurotischer Idiotie bekannt wurde. - Bezüglich unseres Falles sei erwähnt, daß die Eltern noch vier gesunde Kinder hatten; die kleine Patientin war schon seit längerer Zeit krank, hatte Krämpfe, zeigte geistigen Stillstand und verendete im tiefsten Marasmus. Bei der Sektion fiel der große Schädelumfang auf, der leider nicht gemessen wurde; Schädeldecke mit der Dura mäßig verwachsen. Dura gespannt, die weichen Hirnhäute besonders hinten stark ödematös. Am Gehirn waren äußerlich dessen Größe und besonders die verminderte Konsistenz auffallend, die selbst nach mehrwöchentlicher Härtung in Formalin nicht verschwand; die Hemisphärenoberfläche zeigte die sub $\mathrm{C}$ geschilderte partielle Operculisation des Occipitallappens. Bei Einschnitt machte sich eine Weichheit der Marksubstanz bemerkbar, welche auch nach mehrwöchentlicher Härtung im 5proz. Kaliumbichromat nicht schwand, und erst durch eine dreimonatliche Bichromatbeizung im Brutschranke wurde eine leidliche Konsistenz erreicht. Diese schwierige Härtung hat eine unvollkommene Schnittfähigkeit des Großhirns bedungen, welche nur durch eine vielmonatige Durchtränkung mit Celloidin ansgeglichen werden konnte. Verhältnismäßig leicht war das Rautenhirn zu schneiden. Sämtliche Schnitte, die auf Markscheiden gefärbt wurden, machten im Kollodiummantel eine erneute Bichromatbeize von zwei Tagen im Brutschranke durch, denn nur so war eine tadellose Hämatoxylinfärbung nach WeigertKultschitzky zu erzielen.

\section{Großhirn.}

Die lecithinoide Degeneration war durchweg an allen Stellen der Großhirnrinde festzustellen; hierzu bediente ich mich kleinerer Rindenstücke mit Paraffineinbettung (Technik bei A). Es konnte festgestellt werden, daß die lecithinoiden Körner als überwiegend kleine, oft nur defekt färbbare, rundliche Körperchen erscheinen, die zumeist den geblähten Zelleib nicht mehr ganz ausfüllten. Mit Bezugnahme 
auf die einleitend gegebene morphologische Schilderung der lecithinoiden Degenerationsprodukte ist für den vorliegenden Fall eine bereits den Höhepunkt der lecithinoiden Phase überschreitende Degeneration anzunehmen, welchem Umstand die diffuse hellorangegelbe Tinktion durch Scharlachrot entspricht. Überblickt man die durch Markscheidenfärbung erzielten und mit Säurefuchsin überfärbten Rindenpräparate, so fällt auf den ersten Blick eine relative Verarmung der durch lecithinoide Körnelung ausgezeichneten Elemente auf, wie dies besonders lehrreich aus dem Vergleich mit einem anderen Fall von Tay-Sachs hervorging, in welchem sich die lecithinoide Degeneration in voller Blüte befindet. Hier reihen sich die mit größeren hämatoxylinaffinen Körnern strotzend angefüllten Zelleiber und Dendriten viel enger aneinander, somit fallen auf die gleichgroße mikroskopische Grundfläche im letzteren Fall bedeutend mehr degenerierte Elemente wie im vorliegenden Fall; wir haben somit anzunehmen, daß hier eine Verarmung an Nervenzellen durch die mehr oder minder a usge wir k te lecithinoide Phase vorgetäuscht wird. Dieser Umstand macht es verständlich, daß die mit Weigertscher Markscheidenfärbung behandelten Schnitte zur exakten Grenzbestimmung von Rindenfeldern nicht mehr taugten; hierzu sind nur solche Fälle verwendbar, die die lecithinoide Phase in Vollentwicklung enthalten. Im vorliegenden Fall erwies sich speziell die lecithinoide Degeneration der frontoparietalen Gegend derartig vorgeschritten, daß eine deutliche Abgrenzung zwischen $C a$ und $C p$ nicht möglich war, weil eben die ausgeprägte Schichtung mangelte. Anders verhielt sich der Occipitallappen, in welchem die Area striata vermöge der deutlicheren lecithinoiden Degeneration, der ungemein charakteristischen Doppelschichtung und der haarscharfen Abgrenzung ganz sicher zu umschreiben war (s. Abb. 9). Dabei ergab sich die Tatsache, daß das zentrale Sehfeld auf der Cuneuslippe der Calcarina wohl den für den Menschen bekannten Grenzpunkt einhält, jedoch sich auf die ganze Breite des Gyrus lingualis erstreckt, sogar in die F. occipitotemp. (ot) hineingreift und somit gemäß Brod manns Bestimmungen eine pithekoide Ausbreitung bekundet. Bemerkenswert ist die relativ jüngere Degeneration der ontogenetisch älteren Area striata gegen die jüngeren „Assoziationsbezirke“" außerhalb dieser; dieses Verhalten ist ein abermaliger Beweis zugunsten einer systematischen Reihenfolge der Degeneration bei T a y-Sachs, worauf mit Nachdruck F. Naville hinwies. - In den tieferen Rindenschichten fallen Monstergliazellen auf; apolare Gliaelemente überall zerstreut.

An den mit Markscheidenfärbung behandelten Totalschnitten fällt der höchstgradige Markmangel auf. Die Rinde selbst ist überall völlig entmarkt, und so gibt es im ganzen Großhirnmantel keine einzige Stelle, die eine Markfaserung der Rinde darbieten würde, denn 
Zonal- oder Tangential- bzw. Radiärfasern kommen selbst spurweise nicht vor. Das Rindenmark erscheint in der Gegend der Zentralfurche hellblau, hingegen in den polaren Frontalwindungen, im Temporallappen, also in spätmarkreifen Territorien, kaum schattenhaft-bläulich. Sieht man mit dem Mikroskop diese Stellen an, so handelt es sich an ersteren Stellen um degenerierte und defekt gefärbte Markfasern, welche man auch im Balken antrifft, während an letzteren Stellen so gut wie gar kein Mark sichtbar ist.

Geht man zu den zentralen grauen Massen über, so wäre vor allem das Striatum zu erwähnen, das auch nur höchstdegeneriertes und spärliches Mark aufweist. Der Sehhügel zeigt nur in seinem lateralen Kern eine schwächliche Markzeichnung, während alles übrige markleer erscheint. Allein das Pallidum enthält kräftig gefärbte Markzüge, welche, die innere Kapsel durchziehend, zu den subthalamischen grauen Massen (Luysscher Kern, roter Kern) streben. Der Sehhügel, das Striatum und Pallidum enthalten mit hämatoxylinaffinen Körnern besetzte Nervenzellen. Zu betonen wäre, daß selbst die kräftig gefärbte strio-subthalamische Faserung lebhafte Markquellung bzw. Myelinsegmentation sehen läßt.

Im Pedunculus macht sich an der Stelle der fronto- und temporopontinen Bahn eine völlige Markleere bemerkbar.

In der Brücke wäre zuerst die Trigeminushöhe zu schildern. Hier fällt auf den ersten Blick der Unterschied zwischen Hauben- und Fußetage in dem Sinne auf, daß letztere hochgradig markarm ist. Schon die Pyramidenbündel machen sich durch evidente Lichtung bemerkbar und sind makroskopisch nicht nur zahlenmäßig an Markfasern verringert, sondern auch die vorhandenen bekunden Quellungserscheinungen. Höchstgradig litten die Querfasern der Brücke, die allein aus einzelnen feinsten Markkügelchen zusammengesetzte Reihen in sehr spärlicher Zahl repräsentieren, wodurch die charakteristischen Transversalfasern der Brücke ganz schwanden und die Pyramidenbündel in einem hellen, ganz markleeren Gewebe liegen. Die einzelnen Markkügelchen summieren sich dann besonders am ventro-lateralen Brückenrand zu einem hellgrauen Gebiet, zum Brückenar m, der somit als in höchstgradiger Degeneration befindlich bezeichnet werden muß. Im Gegensatz hierzu erscheint die Haubenetage viel markreicher bzw. markgesund. So sind die Bindearme, die Längsbündel, die Wurzelfaserung des Trigeminus ganz intakt, springen daher durch ihre tiefschwarze Farbe förmlich ins Auge; auch die sekundäre Cochlearisbahn ist kräftig, wennschon etwas heller gefärbt, während die Schleife fast dem Zustand der Pyramide gleicht, daher auch nicht die normal-gesättigte Tönung aufweist. - Prinzipiell übereinstimmend verhält sich die Brücke in der Facialishöhe. Die Fußetage erscheint genau so wie in der Trigeminus- 
höhe, also nebst sehr gelichteten Pyramiden fallen die Brückenarme durch ihre hellaschgraue Farbe, d. h. durch ihre höchstgradige Degeneration auf. Auch die Fibrae transversae pontis sind ausgefallen bzw. durch minimale Markkügelchenreihen repräsentiert, und so erscheinen die Pyramiden hier auch in einem markleeren, hellgelben Gewebe eingebettet. Vollkommen normal sind die Bindearme, der Strickkörper (hier wohl schon im Kleinhirn liegend), das hintere Längsbündel, die

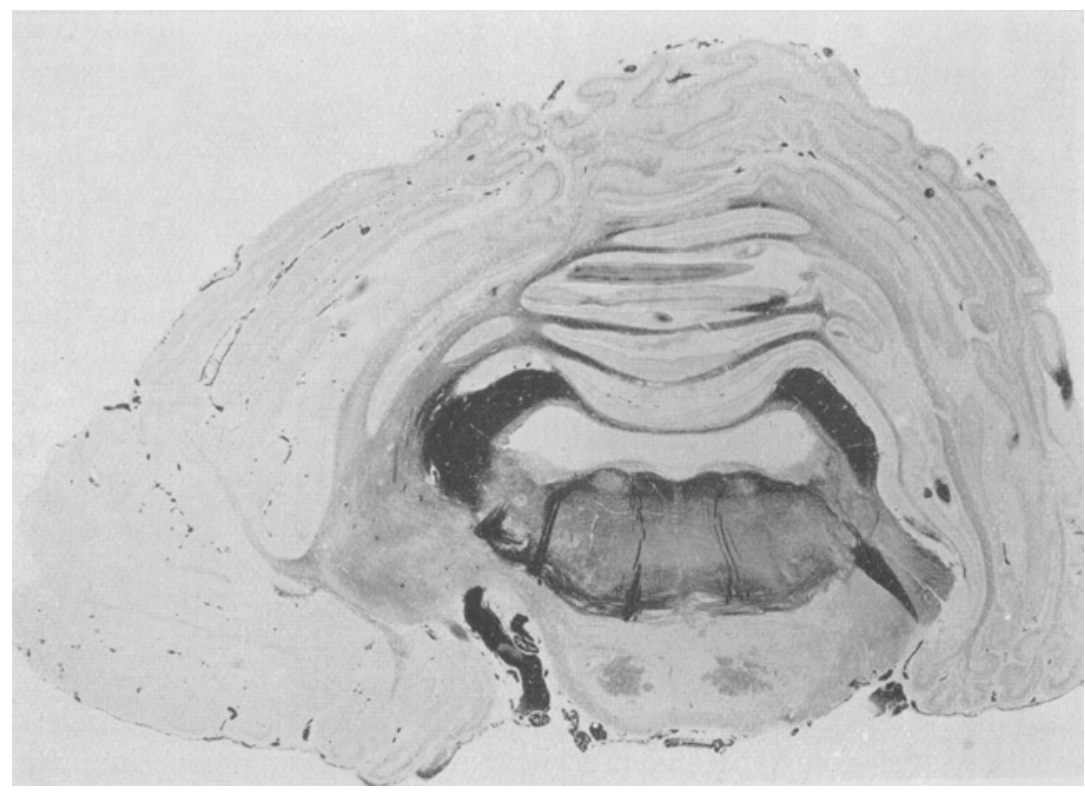

Abb, 12. Querschnitt der Facialisgegend. W e i g e r t s Markscheidenfärbung in meinem neuesten Fall von $\mathbf{T}$ a $y-S$ a $c h$ s. Systemdegeneration des Rautenhirns, welche die Pyramiden, die frontopontine, die ponto-cerebellare (Brïckenarm-)Bahn betrifit, dabei die Bindearme und strickkörper völlig intakt läßt. Beachtenswert gegen die Markleere der ventralen Brückenetage die Markgesundheit der dorsalen Etage, mit anderen Worten: der neencephale Teil der Brücke degeneriert, der paleo-encephale Teil hingegen intakt (phylogenetische Systemdegeneration der Brïcke).

sekundäre Cochlearisbahn, endlich alle Hirnnervenwurzeln dieser Höhe, wie Vestibularis, Facialis und Abducens (s. Abb. 12).

Das verlängerte Mark zeigt Verhältnisse, die sich im wesentlichen mit jenen der Brücke decken. Ganz normal erscheinen hier am Totalschnitt des Rautenhirns die Bindearme und Strickkörper, die als marküppige Gebilde sich bemerkbar machen; ganz normal sind die beiderseitigen olivo-cerebellaren Fasern, die hinteren Längsbündel, die hiesigen Hirnnervenwurzeln wie VIII, IX, X und XII. Pyramiden und Schleifen gelichtet. Hervorzuheben wäre so in der Brücke wie in der Oblongata die allörtliche Nervenzelldegeneration, somit erscheinen 
selbst jene Nervenkerne aus geblähten und mit hämatoxylinaffinen Körnern besetzten Zellkörpern bestehend, die als Ursprung für die ganz normal aussehenden Hirnnervenwurzeln dienen.

Kleinhirn. Das lehrreichste Bild gewinnen wir durch die Weigertschen Markscheidenpräparate, denn man sieht erstens auf Grund der lecithinoiden Degeneration die Ausbreitung der Nervenzelldegeneration, zweitens das Verhalten der Markfasern, und so geben solche Präparate Aufschluß über das ganze Neuron.

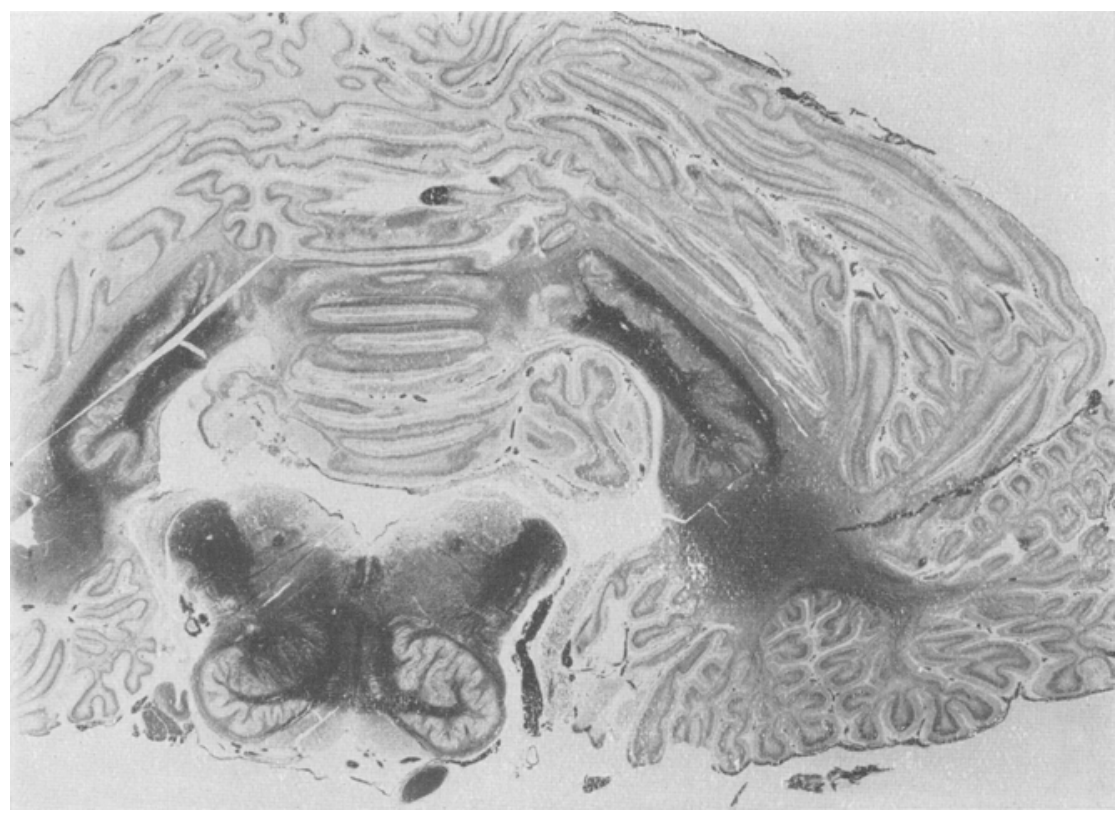

Abb. 13. Querschnitt der Oblongata samt Kleinhirn meines neuesten Falles von T a y - S a ch s. W e i g erts Markscheidenfärbung; Näheres im Text.

Um die lecithinoide Degeneration der Kleinhirnrinde einwurfsfrei darzustellen, ist eine tadellose Chromierung des ganzen Celloidinblockes, wie der Totalschnitte des Rautenhirns, ferner eine vorsichtige Differenzierung eine unerläßliche Bedingung (s. Abb. 13). Gelungene Präparate gewähren dann einen prachtvollen Anblick: man sieht die gesamte Rinde des Kleinhirns, so jene der Hemisphären wie des Wurms, einförmig und höchstgradig degeneriert. Diese allörtliche Rindenentartung macht sich durch zwei dunkle, zonal-parallel verlaufende Streifen bemerkbar, wobei der breitere, kompaktere und innere der Körnerschicht, während der schmälere, lockere und äußere der Molekularschicht entspricht; zwischer 
diesen zwei schwarzgefärbten Schichten verläuft ein heller Streifen als Schicht der Purkinjeschen Nervenzellen, in welcher zerstreut degenerierte Exemplare liegen. Im speziellen wären folgende Momente hervorzuheben. Die Nervenzellen der Körnerschicht sind an Zahl entschieden reduziert, die vorhandenen mit lecithinoiden Körnern spärlich besetzt; die Purkin jeschen Nervenzellen verhalten sich wie die Großhirnrindenzellen, enthalten somit kleinkörnige, stellenweise zahlenmäßig reduzierte hämatoxylinaffine Körner; endlich erscheinen die Nervenzellen der Molekularschicht gleichfalls in lecithinoider Degeneration befindlich, doch sind die Entartungskörner relativ wohlerhalten, d.h. tiefblau gefärbt und gleichgroß, ohne Spuren des Zerfalls.

Die Markäste der Kleinhirnwindungen erscheinen so gut wie markfaserleer, nur am Boden gewisser Läppchen bemerkt man schon makroskopisch Verbindungszüge, z. B. zwischen den basalen Läppchen, wie Lobus gracilis und biventer, dann innerhalb der Windungsbezirke des Lobus quadrangularis, indem mehr ventral liegende Gyri mit dorsalen vermöge von schief-vertikal verlaufenden Markzügen verbunden werden. Diese „Assoziationszüge" der Kleinhirnrinde begrenzen von außen das große zentrale Marklager, welches dem Brückenarm entspricht und durch seine hell-aschgraue Farbe auffällt; dieser besteht aus feinsten Marktröpfchen, enthält nirgends wohlgeformte Nervenfasern, ist daher im höchsten Grad degeneriert.

Von den Kleinhirnkernen wäre in erster Reihe der Nucleus dentatus zu erwähnen, der in seiner Markfaserzeichnung nichts Abnormes, allein lecithinoid degenerierte Nervenzellen darbietet, ebenso wie alle Nebenkerne. Im Hilus des Dentatus erscheint die tiefschwarze Markmasse des Bindearms, während auswärts einer Markschale gleich die kompakte, völlig normale Faserung des Strickkörpers verläuft, welche sich vom schwer entarteten Markzentrum der Hemisphären, d. h. vom Brückenarm in der denkbar schärfsten Weise absetzt.

Bevor wir das Kleinhirn verlassen, werfen wir einen Blick auf das Bielschowskysche Fibrillenpräparat. Als auffallend ist vor allem die geringe Breite der Rinde zu bezeichnen, die, weil gleichmäßig verbreitet, als eine angeborene Unterentwicklung aufzufassen ist; ferner macht sich eine Verödung aller Elemente bemerkbar, so daß die Rindenstruktur als sehr verarmt erscheint; schließlich ist als generelles Motiv die Nacktheit der Purkinjeschen Nervenzellen hervorzuheben nebst dem vollkommenen Mangel an tiefen Tangentialaxonen, ein Moment, welches den Ausfall von Korbzellenaxonen anzeigt. - Die Bergmannschen Fasern, wie auch die gliöse Zonalschicht der Kleinhirnrinde, zeigen eine Vermehrung bzw. Verdichtung.

Das Rückenmark bietet am Fibrillenpräparat das bekannte 
typische Bild der Nervenzellschwellung, und hervorzuheben wären hier die sub B geschilderten Achsenschwellungen der grauen Substanz. Erwähnenswert ist das Markscheidenbild, an welchem außer dem oben geschilderten Sulcus cylindricus als embryonale Remanenz besonders der diffuse Myelinzerfall der grauen Substanz auffällt. Alle gröberen Nervenfasern weisen an ihrer Markhülle Netzfiguren, Blähungen und Zerfall in Markkugeln auf, während die feineren Markfasern zahlreiche Varicositäten zeigen. Es ist somit zweifellos; daß auch im Rückenmark Degeneration nicht allein an Nervenzellen, sondern auch an Nervenfasern stattfand. In bezug auf die Nervenzellen wäre hervorzuheben, daß deren Schwellung gegen jene der Rindenzellen jüngeren Datums sein muß, denn es finden sich besonders im Hinterhorn nur mit gequollenem Hyaloplasma, im Vorderhorn nur partiell mit hämatoxylinaffinen Körnern beladene Nervenzellen, so daß der Degenerationsprozeß im Rückenmark entschieden jünger ist gegen jenen der Großhirnrinde, in welcher die lecithinoide Phase fast überschritten erscheint.

Zusammenfassung. Im obigen handelte es sich um einen etwas länger dauernden Fall von infantil-amaurotischer Idiotie, welcher ein, um ein halbes bis ganzes Jahr höheres Alter erreichte als die typischen Fälle von Ta y-Sachs. Diesem längeren Bestand des Prozesses wäre in erster Linie zuzuschreiben, daß die anatomischen Veränderungen vorgeschrittener sind, worauf der Utbergang der lecithinoiden Nervenzelldegeneration in die lipoide Phase, ferner die hochgradige Markdegeneration der gesamten cerebro-spinalen Achse, schließlich das Vorwiegen der Axonschwellungen hinweisen. Eine spezielle Beachtung verdient besonders die Markdegeneration, die sich in Blähungen, in Bildung von Netzfiguren und Myelinkugeln kundgibt und als ein Beweis dafür gelten kann, daß in der Myelopathologie der Ta y - Sachsschen Fälle außer der von Schaffer, Naville und Bielschowsk y betonten Markhemmung auch degenerative Veränderungen eine Rolle spielen können. Besonders interessant erscheint die systematische Ausbreitung der Markdegeneration, worauf im vorliegenden Fall die kombinierte Affektion der cerebro-ponto-cerebellaren Neuronen, d.h. der fronto-pontinen Bahn und des Brückenarms deutet; es ist dies ein Verhalten, mit welchem die Markgesundheit der übrigen Kleinhirnsysteme, wie Bindearme und Strickkörper, lebhaft kontrastieren. Im Dollinger schen Fall erhob Bielschow s y gleichfalls die Degeneration der Brückenarme. An dieser Stelle wäre darauf zu verweisen, daß in Fällen von familiärer Idiotie mit ausgeprägten Kleinhirnveränderungen verschiedene Systeme ergriffen sein können; so wies bekanntlich Bielschowsky für seine Fälle von spätinfantiler Form die Degeneration der Nuclei dentati bzw. der Bindearme nach, während gleichzeitig die Brückenarme und Strickkörper markgesund waren. - Ein spezielles In- 
teresse erregt das Verhältnis der Markfaserdegeneration zur Nervenzelldegeneration. Würde erstere von letzterer allein abhängen, so müßten sämtliche Markfasern identisch degeneriert sein, da doch die Nervenzellen mehr oder minder gleichmäßig ergriffen sind. Da dies aber nicht zutrifft, haben wir anzunehmen, daß einzelne Marksysteme aus irgendeinem Grund eine raschere Entartung erleiden; möglich, daß hier die phylo- und ontogenetische Labilität, welcher die in der embryologischen Reihenfolge jüngsten Bahnen unterliegen, bestimmend ist. Doch vermag diese Begründung nicht immer auszureichen; hierauf deutet die Degeneration des Bindearms in Bielschowskys spätinfantilen Fällen, welcher eine phylo- und ontogenetisch ältere, daher auch stabilere Bildung ist als die fronto-pontine Bahn bzw. der Brückenarm. Somit wäre es am richtigsten, wenn wir in nichtpräjudizierlicher Weise einfach die Tatsache festlegen, daß bei mit Kleinhirnveränderungen ver bundener familiärer Idiotie verschiedene Kleinhirnsysteme, also bald im Sinne einer rubro-cerebellaren (Bindearm), bald in jenem einer pontocerebellaren (Brückenarm) Degeneration leiden können. - Hinsichtlich den feinsten Kleinhirnveränderungen handelt es sich um die Entblößung der Purkinjeschen Nervenzellen, worauf Bielschowsky und Schaffer gleichzeitig (1913) hinwiesen; auf diese Weise kommt der Bielschowskysche cerebellopetale Degenerationstypus zustande.

Aus obigen Befunden ergeben sich folgende Schlüsse.

1. Die infantil-amaurotische Idiotie besteht histopathologisch in der allörtlichen Schwellung der Nervenzellen, die ganz anfänglich durch Quellung des Hyaloplasmas bedingt ist; auf diese Quellungsphase folgt die Fällungsphase von Degenerationsprodukten, die für die infantile Form in den charakteristischen lecithinoiden Körnern besteht, und es ist ein in histopathologischer Beziehung fast beispielloser Zustand, welcher in der gleichförmigen lecithinartigen Degeneration aller Nervenzellen der cerebrospinalen Achse besteht. Gleichzeitig degeneriert die dendritische Glia in Form von Monstergliazellen, die schließlich auch dem Zerfall zusteuern, während die apolaren Gliazellen rein als Transportelemente fungieren. Verfaserung der Glia kann wohl vorkommen und dürfte hauptsächlich in der Kleinhirnrinde eine mehr oder minder konstante Erscheinung sein. Somit degeneriert alles Ektodermale, mit welcher Tatsache in der denkbar schärfsten Weise die völlige Ruhe des Blutgefäß-Bindegewebeapparats kontrastiert. Und so können wir sagen, daß die infantile Form in einer idealen Weise die elektive Affektion des zentralen Nervensystems verwirklichte, indem eben alles Ektodermale erkrankt ist, und dieses Verhalten entspricht der von mir aufgestellten ektodermalen Elektivität bei völliger. Verschonung von allem Mesodermalen. Es handelt sich also um eine Er. 
krankungsform gemäß der Keimblattwahl, die fernerhin wesentlich gesteigert wird durch die innerhalb der ergriffenen ektodermalen Elemente stattfindende engere Wahl gewisser Systeme, wie der cerebro-pontinen und ponto-cerebellaren Neuronen (frontopontine Bahn und Brückenarm), sowie der Pyramidenbahn. Somit wird die Keimblattwahl durch eine Systemwahl ergänzt und dadurch nur noch schärfer umschrieben. Keimblatt- und Systemwahl stellen nach meinen Erörterungen a. a. O. die spezifisch-histologischen Kennzeichen der Heredodegeneration dar, mit anderen Worten: die Heredodegeneration ist $d u r c h$ ein eigenes histopathologisches Syndrom gekennzeichnet, dessen Merkmale auf Grund der entwicklungsgeschichtlichen Wahl in der Form der ektodermalen und systematischen Elektivität gegeben ist. Doch kommt den systematischen heredodegenerativen Krankheiten noch eine sog. Seg mentwahl zu, die besagt, daß diese sich innerhalb der Grenzen eines entwicklungsgeschichtlichen Segments, wie Rückenmark, Rautenhirn, Vorderhirn bewegen; doch kommen auch Segmentkombinationen vor wie Rückenmark + Rautenhirn, Vorderhirn + Rautenhirn, Vorderhirn + Rückenmark, bzw. Kombination aller Segmente, woraus eine allörtliche Affektion resultiert, wie dies die infantilamaurotische Idiotie zeigt.

2. Die Anatomie der infantil-amaurotischen Idiotie erheischt Ergänzungen bzw. eine Revision. Vor allem in makroskopischer $\mathrm{Be}$ ziehung; der neueste Dollinger-Bielschowskysche Fall beweist, daß es makroskopische Veränderungen bei Tay-Sachs gibt (Verhärtungen nebst Verflüssigung der Marksubstanz der Großhirnhemisphären); auch mein vorliegender Fall bot bauptsächlich für die Marsubstanz Konsistenzveränderung. In beiden Fällen handelte es sich um einen sehr protrahierten Prozeß, wodurch sich gröbere Alterationen infolge des längeren Bestandes der Krankheit entwickeln konnten. Ferner wäre auf gewisse Merkmale der abnormen Anlage zu verweisen, wie z. B. klaffende Sylviussche Spalte, partielle Operculisation des Occipitallappens, fötale Furchung des Rückenmarkseitenstrangs. -Mikroskopisch ist gegenüber den bisherigen Kenntnissen darauf zu verweisen, da $B$ bei gehörig langer Entwicklung des Prozesses nicht allein die Nervenzellen, sondern auch die Achsenzylinder eine degenerative Blähung erleiden, daher bei der infantilen familiären Idiotie das Neuron in allen seinen Bestandteilen die pathologische Veränderung erleiden kann. - Ferner verdient die im Sinne der ontogenetischen Reihenfolge sich entwickelnde bezirkartige Degeneration hervorgehoben zu werden, wonach z. B. die ontogenetisch ältere Area striata als eine stabilere Formation gegen die ontogenetisch jüngeren, also labileren Assoziationsgebiete des Occipitotemporallappens eine verzögerte Dege- 
616 K. Schaffer: Tatsächliches und Hypothetisches aus der Histopathologie usw.

neration bekundet; letztere bedingt das interessante in Abb. 9 wiedergegebene Bild, das uns die Area striata noch in florider Degeneration befindlich vorführt, hingegen erscheinen z. B. der außerhalb dieses Zentrums liegende Gyrus fusiformis und die Gyri occipitales in der Degeneration derartig vorgeschritten, daß eine schärfere Rindenschichtung verloren ging. - Schließlich sei betont, daß, obschon die Schwellung der Nervenzellen eine für das zentrale Nervensystem allörtliche ist, dem Degenerationstempo sich doch entnehmen läßt, daß 1. der Prozeß von der Großhirnrinde gegen das Rückenmark hinabsteigt, worauf die anfänglichere Affektion der Nervenzellen im Rückenmark verweist (überwiegende Quellungsphase und nur beginnende Fällungsphase derselben); 2. der Prozeß selbst in der Großhirnrinde eine topische Verteilung dadurch bekundet, daß dieser im Occipitallappen im großen und ganzen inzipient gegen jenen des Frontal- und Temporallappens erscheint. Somit ist hervorzuheben, daß die allörtliche Nervenzelldegeneration areale und segmentale Betonung aufweist; erstere durch das stärkere bzw. zeitlichere Befallensein der Assoziationsgebiete bzw. durch die relative Verschonung der Area striata, letztere durch die verzögerte Degeneration der Nervenzellen des Rückenmarks.

3. Die Schwellung der Nervenzellen - bei der familiären Idiotie in der denkbar schärfsten Weise demonstriert - gewinnt eine gesteigerte Bedeutung durch die Tatsache, daß man diese Erscheinung auch bei anderen heredodegenerativen Formen antrifft. So fand ich diese selbst bei so eminent-chronisch familiären Krankheiten, wie die heredo-cerebellare Ataxie und die spastische Heredodegeneration, allerdings nicht in dominanter Entwicklung wie bei Tay-Sachs. Und da nach obigen Feststellungen die Schwellung bei der familiären Idiotie durch die Quellung des Hyaloplasmas als primäre Erscheinung bedingt wird, so erscheint die krankhafte Veränderung des Hyaloplasmas die grundlegende histopathologische Erscheinung bei der Heredodegeneration im allgemeinen zu sein. Somit entwickelt sich die primäre heredodegenerative Veränderung aus dem ektodermalen Hyaloplasma; diese entspricht. - wie oben bemerkt - einer Erkrankungsform gemäß der Keimblattwahl, welche eine engere bzw, allgemeinere sein kann, jè nach dem allein das neuronale bzw. auch noch das gliöse Hyaloplasma die progressive Degeneration erleidet. 